\title{
Modeling long-term volcanic deformations at the Kusatsu-Shirane and Asama volcanoes, Japan using the GNSS coordinate time series
}

Hiroshi Munekane ( $\triangle$ munekaneh96nu@mlit.go.jp )

Geospatial Information Authority of Japan https://orcid.org/0000-0002-3268-9266

\section{Research Article}

Keywords: Kusatsu-Shirane volcano, Asama volcano, Global Navigation Satellite System, Crustal deformation, Oblate spheroid

Posted Date: April 21st, 2021

DOI: https://doi.org/10.21203/rs.3.rs-433272/v1

License: (a) (i) This work is licensed under a Creative Commons Attribution 4.0 International License.

Read Full License 
1 Modeling long-term volcanic deformation at the Kusatsu-Shirane 2 and Asama volcanoes, Japan using the GNSS coordinate time series

$4 \quad$ Hiroshi Munekane, Geography and Crustal dynamics Research Center, Geospatial Information Authority of Japan, Ibaraki 305-0811, Japan, munekane-h96nu@mlit.go.jp 


\section{Abstract}

7 Long-term deformations of the Kusatsu-Shirane and Asama volcanoes in central Japan were

8 investigated using Global Navigation Satellite System (GNSS) measurements. Large postseismic

9 deformations caused by the 2011 Tohoku earthquake — which obscure the long-term volcanic deformations — were effectively removed by approximating the postseismic and other recent tectonic

deformations in terms of quadrature of the geographical eastings/northings. Subsequently, deformation 12 source parameters were estimated by the Markov Chain Monte-Carlo (MCMC) method and linear inversion. The deformation source of the Kusatsu-Shirane volcano was found to be a sill-like oblate 14 spheroid located a few kilometers northwest of the Yugama crater at a depth of approximately five km, while that of Asama was also estimated to be a sill-like oblate spheroid located at the western flank of 6 the edifice at a depth of approximately $13 \mathrm{~km}$, along with the previously reported shallow east-west 17 striking dike at a depth of approximately $1 \mathrm{~km}$. It was revealed that 1) volume changes of the Kusatsu-Shirane deformation source and the shallow deformation source of Asama were correlated with the volcanic activities of the corresponding volcanoes, and 2) the Asama deep source has been steadily losing volume, which may indicate that the volcano will experience less eruptions in the near future.

21

\section{Keywords}

Kusatsu-Shirane volcano, Asama volcano, Global Navigation Satellite System, Crustal deformation, Oblate spheroid

\section{Introduction}

Monitoring of volcanic deformation is a powerful tool to assess a potential volcanic hazard. Volcanic deformation may be a manifestation of pressure or volume changes in underlining magma chambers (e.g. Ozawa et al. 2004), or may sometimes be related to intrusion from sources in the form of diking (e.g. Hotta et al. 2016). Many volcanoes exhibit deformation prior to eruption; monitoring the deformation allows us to anticipate the crisis beforehand and prepare for the ongoing hazard.

The Kusatsu-Shirane volcano is an active volcano located in central Japan (Figures 1, 2). It is a complex volcano with notable groups of pyroclastic cones named Shirane-san, Ainomine, and Motoshirane-san 
starting from north to south (Japan Meteorological Agency 2013). All historic eruptions up to 2018 had occurred in the summit area of Shirane-san, while recent volcanic activities were mostly phreatic eruptions in the Shirane-san region with a Volcanic Explosivity Index (VEI) (Newhall and Self 1982) of 1 or 2 including the latest one during 1982-1983.

A summary of recent volcanic activities in the Shiranesan area, as per the Japan Meteorological Agency (2021a), is as follows: In 2014, number of volcanic earthquakes around the Yugama crater and the area to the south of it increased from March to mid-August, and thermal demagnetization under the Yugama crater was observed from May to July. Inflation of a shallow source was observed from May to the end of November 2015. In 2018, the number of volcanic earthquakes around the Yugama crater increased in April, and thermal demagnetization under the Yugama crater was observed from April to July. In addition, grayish water was observed in the Yugama crater from June to July. Inflation of a shallow source was observed from the end of April till the end of August. The number of volcanic earthquakes around the Yugama crater increased again in September. Since then, volcanic tremor, grayish water in the Yugama crater, and inflation of a shallow source have been observed several times.

In 2018, a phreatic eruption occurred at the Kagamigaike-kita pyroclastic cone in Motoshirane-san (e.g. Himematsu et al. 2020), with one reported casualty.

Asama volcano is one of the most active volcanoes in central Japan, located approximately $25 \mathrm{~km}$ south of the Kusatsu-Shirane volcano (Figures 1,2). It is a complex volcano that consists of three volcanoes, Kurofu, Hotokeiwa, and Maekake in order of age. Maekake is the youngest which started erupting approximately 10,000 years ago; its current activities are concentrated at the Kamayama crater (Japan Meteorological Agency 2013). It has experienced large explosive eruptions (VEI >4) in 1108, 1128, and 1783 (Japan Meteorological Agency 2013).

A summary of recent volcanic activities in the Asama volcano, as per the Japan Meteorological Agency (2021b), is as follows: From 2015 till 2018, the volcanic activity of the Asama volcano was elevated, resulting in increase in the number of volcanic earthquakes, and enhanced fumarol and amount of $\mathrm{SO}_{2}$. During the period the Asama volcano experienced small eruptions twice in June 2015. In June 2020 , the volcanic activity was elevated again, resulting in the increase in the number of volcanic earthquakes and enhanced amount of $\mathrm{SO}_{2}$.

In recent years, dense networks of geophysical observation systems including the GNSS and tiltmeters have been deployed around these volcanoes by the Geospatial Information Authority of Japan (GSI), 
Japan Meteorological Agency (JMA), and the National Research Institute for Earth Science and Disaster Resilience (NIED) among others. Data from these networks indicate that the volcanic unrest in these volcanoes is often accompanied by inflation of shallow reservoirs or intrusion of a dike in the shallow part of the volcanic edifice. For example, the unrest of the Yugama crater in the Shirane-san cone in the Kusatsu-Shirane volcano in 2014 and 2018 was accompanied by the inflation of a shallow reservoir, possibly in the form of a sill, beneath the Yugama craterat approximately $1.2-1.5 \mathrm{~km}$ above sea level, and resulted in the deformations which were detected by tiltmeter and repeated GNSS surveys in the proximity of the Yugama crater (Japan Meteorological Agency 2018a; Terada et al. 2018). The Asama volcano has experienced small eruptions in 2004 and 2009 (Japan Meteorological Agency 2013). During these periods of eruption, the western part of the volcano exhibited north-south extension, which was interpreted as a manifestation of the intrusion of an east-west striking dike whose top was a few kilometers below ground surface as revealed by continuous GNSS observation (Takeo et al. 2006; Aoki et al. 2013). However, the behavior of deeper sources, possibly a magma chamber that feed heat, gas or magma to the shallower chambers, has not been confirmed for both volcanoes though the existence of such sources has been suggested by deformations detected by continuous GNSS (e.g. Japan Meteorological Agency 2018b) in the case of the Kusatsu-Shirane volcano, or by deformations detected through leveling survey in the case of the Asama volcano (Murase et al. 2007).

One of the difficulties in unraveling the behavior of deep sources, especially in the long-term, lies in the treatment of the tectonic deformations. Due to the coupling of the subducting Pacific plate and the overriding North American (or Eurasia) plate, this area was subjected to a north-east contraction of approximately $0.2 \mathrm{ppm} /$ year prior to the Tohoku earthquake in 2011 (e.g. Sagiya et al. 2000). Following the earthquake, this area was subjected to a northeast-southwest extension exceeding $0.3 \mathrm{ppm} / \mathrm{year}$ in 2013 and decaying with time owing to the postseismic deformation after the Tohoku earthquake (e.g. Geospatial Information Authority of Japan 2014). As an example, the extension of 0.3 ppm/year is equivalent to $3 \mathrm{~mm}$ for a $10 \mathrm{~km}$ baseline. This value is unacceptably large when one deals with subtle volcanic deformations $(\sim 1 \mathrm{~cm})$ detected using a widely spanning GNSS network whose range is typically a few tens of $\mathrm{km}$.

Hence, in this study, we first address the removal of the tectonic deformations from the observed GNSS coordinate time series. Then, with the processed coordinate time series, we determine the possible source locations of the Kusatsu-Shirane and Asama volcanoes using the Markov Chain Monte Carlo (MCMC) 
method (e.g. Munekane et al. 2016). Finally, we estimate the strengths of the estimated sources in terms of volume changes using linear inversion, and discuss the relationship between the estimated strengths and volcanic activities of both volcanoes.

\section{Data and Methods}

We used the GNSS dual-frequency receivers deployed by GSI, JMA, and NIED within a rectangular area spanning $1^{\circ} \times 1^{\circ}$ with both volcanoes located in its central area (Figure 1). We processed the GNSS data using Precise Point Positioning (Zumberge et al. 1997) to obtain a daily GNSS coordinate time series. First, the GNSS ephemeris and clocks are estimated using the MADOCA software (Takasu 2013): the PPP analysis is then conducted using the RTKLIB (Takasu 2020) with the estimated ephemeris and clocks. The GNSS coordinate time series cover the period 2013-2020. They are resampled into 30-day bins to mitigate noises.

\section{Removal of tectonic deformations}

As stated in the introduction, the removal of tectonic deformations is critical in evaluating the longterm behavior of volcanic sources. A common strategy is to represent tectonic deformations through linear trends, and estimate these trends with the GNSS coordinate time series, when volcanic activities are not observed. However, this strategy may not work in this study as the tectonic deformations can not be represented by linear trends as they are affected by postseismic deformations related to Tohoku earthquake (e.g. Tobita 2016). Hence, in this study, we adopt a functional representation of tectonic deformations proposed by Murakami (2005).

Following the study of Murakami (2005), tectonic deformations are represented by the following equation:

$$
T_{i j}=\alpha_{i j 1}+\alpha_{i j 2} \Delta x+\alpha_{i j 3} \Delta y+\alpha_{i j 4} \Delta x^{2}+\alpha_{i j 5} \Delta x \Delta y+\alpha_{i j 6} \Delta y^{2}
$$

where $T_{i j}$ represents the tectonic deformation for the $i$ th component at the $j$ th epoch, and $\Delta x$, $\Delta y$ represent a northward and eastward distance from a reference point, respectively. Note that the parameters corresponding to $\Delta x^{2}$ and $\Delta y^{2}$ are added to the formula from Murakami (2005) to make the equation quadratic.

The GNSS coordinate time series of stations that are at least $20 \mathrm{~km}$ away from the center of each volcano (gray circles in Figure 1) are used to estimate the coefficients of equation (1) at each epoch. To enhance stability of the estimating process, the gradient of each coefficient is constrained - that is, the equation 
is solved as follows:

$$
\left[\begin{array}{c}
\mathbf{d} \\
0 \\
0 \\
0
\end{array}\right]=\left[\begin{array}{c}
\mathbf{G} \\
\beta_{E} \mathbf{H}_{E} \\
\beta_{N} \mathbf{H}_{N} \\
\beta_{U} \mathbf{H}_{U}
\end{array}\right] \mathbf{m}
$$

where $\mathbf{d}$ and $\mathbf{G}$ represent the displacement data and the geometrical factor defined in equation (1), and $\mathbf{H}_{i}(\mathrm{i}=\mathrm{E}, \mathrm{N}, \mathrm{U})$ are gradient operators for parameters representing the East, North and Up components, respectively. $\mathbf{m}$ denotes the model parameters defined in equation $(1) . \quad \beta_{i}(\mathrm{i}=\mathrm{E}, \mathrm{N}, \mathrm{U})$ are hyperparameters representing the East, North and Up components, respectively, which will be determined to minimize the Akaike Baysian Information Criteria (ABIC) (Akaike 1980) described by the following equation:

$$
\operatorname{ABIC}(\mathbf{m}, \beta)=N \log s(\mathbf{m})-\log \left|\sum_{i=E, N, U} \beta_{i}^{2} \mathbf{H}_{i}\right|+\log \left|\mathbf{G}^{T} \mathbf{G}+\sum_{i=E, N, U} \beta_{i}^{2} \mathbf{H}_{i}\right|,
$$

where

$$
s(\mathbf{m})=(\mathbf{d}-\mathbf{G m})^{T}(\mathbf{d}-\mathbf{G m})^{T}+\sum_{i=E, N, U} \beta_{i}^{2} \mathbf{m}^{T} \mathbf{H}_{i} \mathbf{m} .
$$

Equation (2) is first solved with the least-square method for fixed $\beta_{E}^{2}, \beta_{N}^{2}, \beta_{U}^{2}$ :

$$
\hat{\mathbf{m}}=\left(\mathbf{G}^{T} \mathbf{G}+\sum_{i=E, N, U} \beta_{i}^{2} \mathbf{H}_{i}\right)^{-1} \mathbf{G}^{T} \mathbf{d}
$$

where $\hat{\mathbf{m}}$ represents estimated parameter values. Then $\mathrm{ABIC}\left(\hat{m}, \beta_{E}^{2}, \beta_{N}^{2}, \beta_{U}^{2}\right)$ is calculated by replacing $\mathbf{m}$ with $\hat{\mathbf{m}}$ in equation (3). This procedure is repeated for variable $\beta_{E}^{2}, \beta_{N}^{2}, \beta_{U}^{2}$ and the estimated parameter values for which $\mathrm{ABIC}$ is minimum, is adopted.

\section{Determination of source positions/geometries by MCMC}

The GNSS coordinate time series within $20 \mathrm{~km}$ the Kusatsu-Shirane and Asama volcanoes (white circles in Figure 1) are used to determine source positions/geometries. First, we remove tectonic deformations estimated using equation (1) from these coordinate time series. Next, the MCMC analysis is conducted on 15 epochs between 2014.5 to 2020.6 , which are selected in order to determine source positions/geometries and intensities in terms of volume changes. Source positions/geometries are assumed to be constant for all periods. To reduce computational costs, we first estimated the source parameters of the KusatsuShirane source and then estimated the parameters for the Asama sources while keeping those for the Kusatsu-Shirane source fixed. Details of source models employed in the MCMC analysis are descried in the following subsection; the MCMC method employed in this study is described in detail in Munekane 
et al. (2016).

The Kusatsu-Shirane source To represent the deformation source around the Kusatsu-Shirane volcano, we used the analytical model for an arbitrary oriented spheroid with a point-source approximation where the ratio of horizontal axis to vertical axis (axis-ratio) is estimated, instead of considering the absolute semi-axis dimensions (Cervelli 2013; Xue et al. 2020). This source is intended to represent a deep source, which is assumed to be located in the north or north-western part of the Yugama crater (Japan Meteorological Agency 2018b). Notably, there exists a shallow sill-like source in the proximity of the Yugama crater at approximately $1.2--1.5 \mathrm{~km}$ above the sea level (Japan Meteorological Agency 2018a; Terada et al. 2018). We assumed that the deformation caused by this source is negligible at the GNSS stations considered in this study, and have excluded this source in the MCMC estimation. The validity of this assumption is discussed later.

Asama sources We used a shallow dike to represent the expansion source that was frequently observed at the western flank during times of volcanic unrest (e.g. Takeo et al. 2006; Aoki et al. 2013). We adopted the source parameters from Takeo et al. (2006) to represent the source. Furthermore, the analytical model for an arbitrary oriented spheroid with a point-source approximation (Cervelli 2013; Xue et al. 2020) was adopted to represent a possible deep source (e.g. Murase et al. 2007). The estimated source parameters and volume changes for the Kusatsu-Shirane source were fixed to the pre-estimated values during the MCMC estimation for the Asama sources.

\section{Linear inversion for source strengths}

After determining parameters regarding positions/geometries source parameters for the Kusatsu-Shirane and Asama sources, the strengths parameters, in terms of volume change, were evaluated using linear inversion. All the data were used for this process. The strengths were subject to gradient constraint to stabilize the estimated parameters; that is, we solved following equations:

$$
\left[\begin{array}{c}
\mathbf{d} \\
0 \\
\cdots \\
\cdots \\
0
\end{array}\right]=\left[\begin{array}{c}
\mathbf{G} \\
\beta_{0} \mathbf{H}_{0} \\
\cdots \\
\beta_{i} \mathbf{H}_{i} \\
\cdots \\
\beta_{N} \mathbf{H}_{N}
\end{array}\right] \mathbf{m},
$$


Table 1. Estimated source parameters for the Kusatsu-Shirane source.

\begin{tabular}{ccccccc}
\hline & Lon $\left(^{\circ}\right)$ & Lat $\left(^{\circ}\right)$ & Depth $(\mathrm{km})$ & Axis ratio & Strike $\left(^{\circ}\right)$ & Dip $\left(^{\circ}\right)$ \\
\hline & 138.519 & 36.653 & 4.8 & 236.9 & 56.5 & 79.3 \\
\hline Lower bound & 138.508 & 36.647 & 2.8 & 124.8 & 15.8 & 72.0 \\
& & & & & & \\
Upper bound & 138.523 & 36.662 & 6.3 & 340.1 & 129.0 & 85.9
\end{tabular}

Lower and upper bounds represent $95 \%$ credible interval.

where $\mathbf{d}$ and $\mathbf{G}$ denote the deformation data and Green's functions, respectively, and $\mathbf{H}$ and $\beta_{\mathrm{i}}$ represent the smoothing matrix and hyperparameter for the $i$ th source. N represents the number of sources (three in this study). $\beta_{\mathrm{i}}$ is determined by minimizing ABIC similar to the case of equation (3).

\section{Results}

\section{Removal of tectonic deformations}

Figure 3 shows the selected GNSS coordinate time series at non-volcanic sites and volcanic sites (whole GNSS coordinate time series are shown in Figures S1(a) and S1(b)). It can be seen that the coordinate time series agree well with estimated tectonic deformations for non-volcanic sites. At volcanic sites, some deviations between GNSS coordinate time series and tectonic deformations can be observed. For example, some deviations are observed during the period 2013-2015 and after 2018 in the north-south components at the site kshv, which are of volcanic origin as explained later. Overall reduced $\chi^{2}$ is reduced from 181.3 to 2.76 for non-volcanic sites.

\section{Source determination by MCMC}

The Kusatsu-Shirane source Table 1 shows the estimated parameters for the source near the Kusatsu-Shirane volcano. It is located a few kilometers west of the Yugama crater at a depth of approximately five $\mathrm{km}$ (Figure 4). It is to be noted that the source is a highly oblate spheroid (axis ratio is over 200) with a dip angle close to $90^{\circ}$, which may be approximated as the penny-shaped crack (Fialko et al. 2001).

Figure 4 shows the location of the source and observed and calculated snapshots of displacements between 2014.5 and 2020.6. The reduced $\chi^{2}$ is reduced from 4.21 to 3.92 .

Asama sources Table 2 shows the estimated parameters for the sources under the Asama volcano. In Table 2, source parameters representing a shallow expansion source of the volcano (Takeo et al. 2006), 
Table 2. Estimated source parameters for Asama sources.

\begin{tabular}{rrrrrrrr}
\hline Shallow source & Lon $\left(^{\circ}\right)$ & Lat $\left(^{\circ}\right)$ & Depth $(\mathrm{km})$ & Length $(\mathrm{km})$ & Width $(\mathrm{km})$ & Strike $\left(^{\circ}\right)$ & Dip $\left(^{\circ}\right)$ \\
\hline $\mathbf{1 3 8 . 5 0 0}$ & $\mathbf{3 6 . 4 0 8}$ & $\mathbf{0 . 5}$ & $\mathbf{4 . 1}$ & $\mathbf{2 . 1}$ & $\mathbf{2 9 6}$ & $\mathbf{1 0 1}$ \\
\hline Deep source & Lon $\left(^{\circ}\right)$ & Lat $\left(^{\circ}\right)$ & Depth $(\mathrm{km})$ & Axis ratio & Strike $\left(^{\circ}\right)$ & Dip $\left(^{\circ}\right)$ \\
\hline & 138.478 & 36.440 & 12.6 & 164.5 & 12.8 & 70.7 \\
\hline \\
\hline Lower bound & 138.471 & 36.429 & 11.2 & 138.0 & 3.9 & 68.0 \\
\\
Upper bound & 138.482 & 36.442 & 13.0 & 190.0 & 15.6 & 72.3
\end{tabular}

Lower and upper bounds represent $95 \%$ credible interval. Figures in bold represent values fixed in the MCMC analysis.

which are fixed during the inversion, are also shown. A deep source is found under the western flank of the Asama volcano at approximately $13 \mathrm{~km}$ depth, which is also a highly oblate spheroid (axis ratio is over 100) with dip angle close to $90^{\circ}$, that may be approximated to a penny-shaped crack (Fialko et al. 2001).

Figure 5 shows the location of the sources and the observed and calculated displacements between 2014.5 and 2020.6. The reduced $\chi^{2}$ is reduced from 3.92 to 2.25 .

\section{Estimation of strengths}

Figure 6 shows the estimated strengths in terms of volume changes for sources under the Kusatsu-Shirane and Asama volcanoes.

The volume of the Kusatsu-Shirane source shows steep increase of approximately $5 \times 10^{6} \mathrm{~m}^{3}$ from the end of 2013 to the middle of 2015 . Subsequently, the volume slightly decreases $\left(\sim 1 \times 10^{6} \mathrm{~m}^{3}\right)$ from the middle of 2015 to the end of 2017 . It then gradually increases by approximately $2.5 \times 10^{6} \mathrm{~m}^{3}$ by the middle of 2020.

The volume changes of the shallow source of the Asama volcano are generally small, and show an oscillatory pattern. The source lost approximately $0.2 \times 10^{6} \mathrm{~m}^{3}$ in volume from 2013 through 2014 . It then underwent oscillatory inflation from the beginning of 2015 to the beginning of $2018\left(\sim 0.2 \times 10^{6} \mathrm{~m}^{3}\right)$, after which it lost volume till mid-2020 $\left(\sim 0.2 \times 10^{6} \mathrm{~m}^{3}\right)$ to again gain the volume till the end of the period for which data is available (2020.11). 
The deep source of the Asama volcano shows a general deflation with a plateau from the beginning of 2015 to the end of 2017. It lost approximately $20 \times 10^{6} \mathrm{~m}^{3}$ in volume during the analysis period.

Figure 7 shows the observed and calculated coordinate time series for selected sites (whole GNSS coordinate time series are given in Figures S2(a) and S2(b)). Reasonable fits between observed and calculated coordinate time series are observed. Reduced $\chi^{2}$ is reduced from 5.20 to 2.61 .

\section{Discussion and conclusions}

\section{Influence of 2018 Motoshirane-san eruption and inflation of a shallow source in the vicinity} of the Yugama crater

Here, we evaluate the magnitude of the deformations from deformation sources omitted in this study, to see their impacts on our model estimations.

The first is the deformation caused by the 2018 eruption of the Motoshirane-san. Himematsu et al. (2020) reported that coeruptive deformation amounts to $10 \mathrm{~cm}$ at a maximum while posteruptive deformation is much smaller compared to the coeruptive deformation (approximately $2-3 \mathrm{~cm}$ at a maximum). Hence, we evaluate only coeruptive deformation at our observation sites based on the deformation model presented in Himematsu et al. (2020), whose parameters are summarized in Table S1. As a result, we found that the maximum coeruptive horizontal deformation was as small as $2 \mathrm{~mm}$ at $\mathrm{j} 423$ and the maximum vertical deformation is $0.4 \mathrm{~mm}$ at $\mathrm{j} 423$. As the magnitude of posteruptive deformation is much smaller compared to the coeruptive one (Himematsu et al. 2020), we may conclude that the deformation caused by the 2018 Motoshirane-san eruption is safely ignored in our model estimation.

The second is the deformation caused by inflation of a shallow source in the vicinity of the the Yugama crater in the Shirane-san area (Figure 2(a)). When volcanic activities at the Yugama crater increased in 2014 and 2018, deformations caused by inflation of the source were detected by tiltmeters and repeated GNSS surveys in the proximity of the Yugama crater (e.g. Japan Meteorological Agency 2020). The inflation during the 2014 unrest was much larger (more than a factor of two) than that during the 2018 unrest (e.g. Japan Meteorological Agency 2020). Hence, we evaluate only deformation during the 2014 unrest at our observation sites based on the model presented in Terada et al. (2018), whose parameters are summarized in Table S2. As a result, we found that the maximum horizontal and vertical displacement on out observation sites caused by the shallow source during the 2014 unrest are as small as $1.1 \mathrm{~mm}$ at $\mathrm{j} 423$ and $0.4 \mathrm{~mm}$ at $\mathrm{j} 424$, respectively. Hence we may safely conclude that the shallow source in the 
vicinity of the Yugama crater may not affect the estimation of the deep source in the west of Yugama crater, as conducted in this study.

\section{The Kusatsu-Shirane source}

In Figure 6 (a), one can see that the Kusatsu-Shirane source is generally inflating since 2013, with distinct inflation from late 2013 to 2015, and late 2017 onward. We observed corresponding enhancement of volcanic activities around the Yugama crater in 2014 and 2018 onward as summarized in the introduction. This correlation suggests that the Kusatsu-Shirane source acts as a heat-source for the shallow source that triggers the volcanic activities. In fact, Matsunaga et al. (2020a) and Matsunaga et al. (2020b) presented the three-dimensional electrical resistivity structure under the Kusatsu-Shirane volcano. They found the widely-spreading conductor $(\mathrm{C} 2)$ at a depth of approximately 1-1.5 km observed over an area stretching from the Yugama crater to Motoshirane-san, which has been interpreted as a large-scale hydrothermal fluid reservoir. Further, Matsunaga et al. (2020b) revealed the deep extension of the C2 conductor at least up to the depth of $(7.5 \mathrm{~km})$, which they interpreted a possible magma chamber that drives hydrothermal fluid migration in the $\mathrm{C} 2$ conductor. Considering these structural information, the deep source revealed in this study may be interpreted as a magma chamber that corresponds to the deep extension of the $\mathrm{C} 2$ conductor in Matsunaga et al. (2020b). During its inflation period, this source may provide additional heat to the shallow hydrothermal fluid reservoid that corresponds to the $\mathrm{C} 2$ conductor (Matsunaga et al. 2020a,b) to trigger the volcanic activities at the Yugama crater and possibly at the Motoshirane-san.

\section{Asama sources}

In Figure 6 (b), it can be observed that the volume change of the Asama shallow source shows an oscillatory pattern and inflation occurred from the beginning of 2015 through the beginning of 2018 with a short period of deflation in late 2016. Inflation was observed again in mid-2020. Correspondingly, we observed the enhanced volcanic activities in the Asama volcano, as summarized in the introduction. This correspondence supports the view that the shallow source, a nearly east-west-trending dyke, acts as a deposit of magma, triggering various volcanic anomalies such as increase in volcanic earthquakes (Aoki et al. 2013).

Aoki et al. (2013) reported the S-wave velocity structure in and around the Asama volcano and found the widely-spread low-velocity zone in the western flank of the volcano at a depth of 5-10 km, which was interpreted as a magma chamber that feeds a magma to the shallow dike. The deep source identified in this study was located at the bottom of the low-velocity zone. Hence, we may consider the source as a 
287 deformation.

\section{List of abbreviations}

\section{${ }_{286}$ Author contributions}

part of the magma chamber from which the magma will migrate upward without causing considerable

Murase et al. (2007) found a deep source located under the western flank of the Asama volcano at the depth of $6-8 \mathrm{~km}$ from the leveling data between 1902-2005. The horizontal location of this source is within the margin of error of the deep source in this study. However, there is notable difference in the geometries of the two sources (sphere v.s. spheroid) and the depth (6-8 km v.s. $-13 \mathrm{~km})$. It requires further investigation to determine if these sources may be considered the same. In case these two refer to the same source, the volume changes of the source as revealed in Figure 6 (b) may have an important role in volcanic monitoring since Murase et al. (2007) claim that the temporal changes in the pressure or volume of the source exhibit a strong positive correlation with the eruption frequency. This implies that the Asama volcano will experience few eruptions in the near future because the volume of the deep source rapidly decreased during the study period (2013-2020), as experienced in the period 1943-1967 when fewer volcanic eruptions were observed. For disaster mitigation, it may be important to monitor the volume changes of the deep source using GNSS to estimate inflation, which may be an indicator of the rekindling of volcanic activities.

JMA: Japan Meteorological Agency

NIED: National Research Institute for Earth Science and Disaster Resilience

GSI: Geospatial Information Authority of Japan

MCMC: Markov Chain Monte-Carlo method

VEI: Volcanic Explosivity Index

\section{Availability of data and materials}

GNSS data used in this study are available upon request from the respective agencies.

HM designed the research, came out the corresponding analysis, and wrote the article. 


\section{Author information}

Affiliations

Crustal Deformation Research Division, Geospatial Information Authority of Japan, 1 Kisasato, Ibaraki, Tsukuba 3050811, Japan Hiroshi Munekane

\section{Acknowledgments}

The author is thankful for the fruitful discussion with Drs. Akihiko Terada and Yasuo Matsunaga at the Volcanic Fluid Research Center, Tokyo Institute of Technology. Part of the GNSS data used in this study was provided by JMA and NIED. Some of the figures are drawn using the Generic Mapping Tool (GMT) (Wessel et al. 2019).

\section{References}

Akaike H (1980) Likelihood and the Bayes procedure. Traboj Estad Invest Operat 31:143-166.https://doi.org/10.1007/BF02888350

Aoki, Y, Takeo M, Ohminato T, Nagaoka Y, Nishida K (2013) Magma pathway and its structural controls of Asama Volcano, Japan. Geol. Soc. Lond. Spec. Publ. 380:67-84.https://doi.org/10.1144/SP380.6

Cervelli PF (2013) Analytical expressions for deformation from an arbitrarily oriented spheroid in a half-space, Eos Trans. AGU. V44C-06

Fialko Y, Khazan Y, Simons M (2001) Deformation due to a pressurized horizontal circular crack in an elastic half-space, with applications to volcano geodesy. Geophys J Int 146:181-190.https://doi.org/10.1046/j.1365-246X.2001.00452.x

Geospatial Information Authority of Japan (2014) Crustal Deformations of Entire Japan. In: Report of Coordinating Comittee for Earthquake Prediction 91.

https://cais.gsi.go.jp/YOCHIREN/report/kaihou91/01_03.pdf Accessed 20 Jan 2021

Himematsu Y, Ozawa T, Aoki Y (2020) Coeruptive and posteruptive crustal deformation associated with the 2018 Kusatsu-Shirane phreatic eruption based on PALSAR-2 time series analysis. Earth Planets Space 72:116.https://doi.org/10.1186/s40623-020-01247-6

Hotta, K, Iguchi M, Tameguri T (2016) Rapid dike intrusion into Sakurajima volcano on August 15, 2015, as detected by multi-parameter ground deformation observations. Earth Planets Space 
68:68.https://doi.org/10.1186/s40623-016-0450-0

Japan Meteorological Agency (2013) National catalogue of the active volcanoes in Japan (the fourth edition, english version). https://www.data.jma.go.jp/svd/vois/data/tokyo/STOCK/souran_eng/menu.htm. Accessed 19 Jan. 2021

Japan Meteorological Agency (2018a) Volcanic activity of the Kusatsu-Shiranesan Volcano (January 2017-June 2017). In: Report of Coordinating Comittee for Prediction of Volcanic Eruption 127. https://www.data.jma.go.jp/svd/vois/data/tokyo/STOCK/kaisetsu/CPVE/Report/127/kaiho_127_08.pdf Accessed 20 Jan 2021 (in Japanese)

Japan Meteorological Agency (2018b) Volcanic activity of the Kusatsu-Shiranesan Volcano (June 2018-September 2018). In: Report of Coordinating Comittee for Prediction of Volcanic Eruption 131. https://www.data.jma.go.jp/svd/vois/data/tokyo/STOCK/kaisetsu/CPVE/Report/131/kaiho_131_12.pdf Accessed 20 Jan 2021 (in Japanese)

Japan Meteorological Agency (2020) Volcanic activity of the Kusatsu-Shiranesan Volcano (June 2020-November 2020). In: Report of the 147 th Coordinating Comittee for Prediction of Volcanic Eruption 147. https://www.data.jma.go.jp/svd/vois/data/tokyo/STOCK/kaisetsu/CPVE/shiryo/147/147_1_1.pdf Accessed 19 Feb 2021 (in Japanese)

Japan Meteorological Agency (2021a) Volcanic activity of the Kusatsu-Shiranesan Volcano in histrical era. https://www.data.jma.go.jp/svd/vois/data/tokyo/305_Kusatsu-Shiranesan/305_history.html Accessed 11 Mar 2021 (in Japanese)

Japan Meteorological Agency (2021b) Volcanic activity of Asama volcano in histrical era. https://www.data.jma.go.jp/svd/vois/data/tokyo/306_Asamayama/306_history.html Accessed 11 Mar 2021 (in Japanese)

Matsunaga Y, Kanda W, Takakura S, Koyama T, Saito Z, Seki K, Suzuki A, Kishita T, Kinoshita Y, Ogawa Y (2020a) Magmatic hydrothermal system inferred from the resistivity structure of Kusatsu-Shirane Volcano. J Volcanol Geotherm Res 390:106742.https://doi.org/10.1016/j.jvolgeores.2019.106742

Matsunaga Y, Kanda W, Koyama T, Takakura S, Nishizawa T (2020b) 3-D resistivity structure model around Kusatsu-Shirane Volcano revealed by broadband magnetotellurics. paper presented at the 
AGU Fall Meeting, Online, 1-17 December 2020.

https://agu.confex.com/agu/fm20/meetingapp.cgi/Paper/723856

Munekane H, Oikawa J, Kobayashi T (2016) Mechanisms of step-like tilt changes and very long period seismic signals during the 2000 Miyakejima eruption: Insights from kinematic GPS. J Geophys Res Solid Earth 121:2932-2946.https://doi.org/10.1002/2016JB012795

Murakami M (2005) Magma plumbing system of the Asama volcano inferred from continuous measurements of GPS, Bull Volcanol Soc Japan 50:347-361.https://doi.org/10.18940/kazan.50.5_347 (in Japanese with English abstract)

Murase M, Ono K, Ito T, Miyajima R (2007) Time-dependent model for volume changes in pressure sources at Asama volcano, central Japan due to vertical deformations detected by precise leveling during 1902-2005. J Volcanol Geotherm Res 164:54-75.https://doi.org/10.1016/j.volgeores.2007.04.001

Newhall CG, Self S (1982) The Volcano Explosivity Index (VEI): an estimate of explosive magnitude for histrical volcanism. J Geophys Res 87:1231-1238.https://doi.org/10.1186/s40623-016-0450-0

Ozawa S, Miyazaki S, Nishimura T, Murakami M, Kaidzu M, Imakiire T, Ji X (2004) Creep, dike intrusion, and magma chamber deflation model for the 2000 Miyake eruption and the Izu islands earthquake. J Geophys Res Solid Earth 109:B02410.https://doi.org/10.1029/2003JB002601

Sagiya T, Miyazaki S, Tada T (2000) Coutinuous GPS Array and Present-day Crustal Deformation of Japan. Pure Appl Geophys 157:2303-2322.https://doi.org/10.1007/PL00022507

Takasu T (2013) Development of multi-GNSS orbit and clock determination software MADOCA. Paper presented at the 5th Asia Oceania Regional Workshop on GNSS, Hanoi, 1-3 December 2013

Takasu T (2020) RTKLIB: An open software program package for GNSS positioning. http://www.rtklib.com. Accessed 19 Jan. 2021

Takeo M, Aoki Y, Ohminato T, Yamamoto M (2006) Magma supply path beneath Mt. Asama volcano, Japan, Geophys Res Lett 33:L15310.https://doi:10.1029/2006GL026247

Terada A, Kanda W, Ogawa Y, Aoyama Y, Yamamoto M, Tsutsui T, Okura T, Noguchi R (2018) The phreatic eruption on 23 January 2018 at Mt. Moto-Shirane of Kusatsu-Shirane volcano, Japan: geophysical observations and implications. paper presented at the Japan Geoscience Union Meeting, Makuhari, 20-24 May 2018. https://confit.atlas.jp/guide/event-img/jpgu2018/SVC41-37/public/pdf (in Japanese) 
Tobita M (2016) Combined logarithmic and exponential function model for fitting postseismic GNSS time series after 2011 Tohoku-Oki earthquake. Earth Planets Space

68:41.https://doi.org/10.1186/s40623-016-0422-4

Wessel, P, Luis, JF, Uieda, L, Scharroo, R, Wobbe F, Smith, WHF, Tian, D (2019) The Generic

Mapping Tools version 6. Geochemistry, Geophysics, Geosystems

20:55565564.https://doi.org/10.1029/2019GC008515

Xue X, Freymueller J, Lu Z (2020) Modeling the posteruptive deformation at Okmok based on the GPS and InSAR time series: Changes in the shallow magma storage system. J Geophys Res Solid Earth 125:e2019JB017801. https://doi.org/10.1029/2019JB017801

Zumberge JF, Heflin MB, Jefferson DC, Watkins MM, Webb FH (1997) Precise point positioning for the efficient and robust analysis of GPS data from large networks. J Geophys Res Solid Earth 102:5005-5017.https://doi.org/10.1029/96JB03860

\section{Figure legends}

Figure 1 Short title Location of study area and distribution of observation sites. Detailed legend Location of studied area and distribution of observation sites. Inlet shows study area. Active volcanoes are shown as triangles. Circles represent GNSS sites used in study. Grey circles are those more than 20km away from the Kusatsu-Shirane and Asama volcanoes and used in estimation of parameters representing tectonic deformations.

Figure 2 Short title Enlarged maps around Kusatsu-Shirane and Asama volcanoes. Detailed legend Enlarged maps around a) Kusatsu-Shirane volcano, and b) Asama volcano.

Figure 3 Short title GNSS coordinate time series and estimated tectonic deformations at selected sites. Detailed legend GNSS coordinate time series and estimated tectonic deformations at selected sites. Black circles denote GNSS coordinate time series and red lines represent tectonic deformations estimated using equation (1). Error bars represent 1 sigma observation errors. Complete GNSS coordinate time series are given in Figures $\mathrm{S} 1(\mathrm{a})$ and $\mathrm{S} 1(\mathrm{~b})$.

Figure 4 Short title Location of source, and observed and calculated displacements at sites around Kusatsu-Shirane volcano. Detailed legend Location of estimated source and observed and calculated displacements at sites around Kusatsu-Shirane volcano. (a): Location of source. (b): Observed and calculated displacements. Top three panels show horizontal displacements for three periods 
(2014.5-2016.5, 2016.5-2018.6, 2018.6-2020.6) and bottom three panels show those of vertical displacements. Error ellipsoids reflect 1 sigma observation errors.

Figure 5 Short title Location of sources, and observed and calculated displacements at sites around Asama volcano. Detailed legend Location of sources, and observed and calculated displacements at sites around Asama volcano. (a): Location of the sources. (b): Observed and calculated displacements. Legends are the same as for Figure 4.

Figure 6 Short title Estimated volume changes for sources at Kusatsu-Shirane and Asama volcanoes. Detailed legend Estimated volume changes for sources at Kusatsu-Shirane and Asama volcanoes. a) Volume changes of Kusatsu-Shirane source. b) Volume changes of Asama sources. Left and right panels show those of shallow and deep sources, respectively. Dashed lines represent 1 sigma credible intervals. Figure 7 Short title Observed and calculated GNSS coordinate time series after linear inversion at selected sites. Detailed legend Observed and calculated GNSS coordinate time series after linear inversion at selected sites. a) Selected GNSS coordinate time series for sites around Kusatsu-Shirane volcano, b) Those for sites around Asama volcano. Error bars represent 1 sigma observation errors. Complete GNSS coordinate time series are given in Figures S2(a) and S2(b).

Figure S1 Short title GNSS coordinate time series and estimated tectonic deformations at selected sites. Detailed legend GNSS coordinate time series and estimated tectonic deformations at all sites. Legends are the same as for Figure 3. (a) Non-volcanic sites (gray circles in Figure 1), and (b) Volcanic sites (black circles in Figure 1).

Figure S2 Short title Observed and calculated GNSS coordinate time series at all sites after linear inversion. Detailed legend Observed and calculated GNSS coordinate time series at selected sites after linear inversion. a) GNSS coordinate time series at sites around Kusatsu-Shirane volcano, b) Those for sites around Asama volcano. Legends are the same as for Figure 7. 
Figure 1

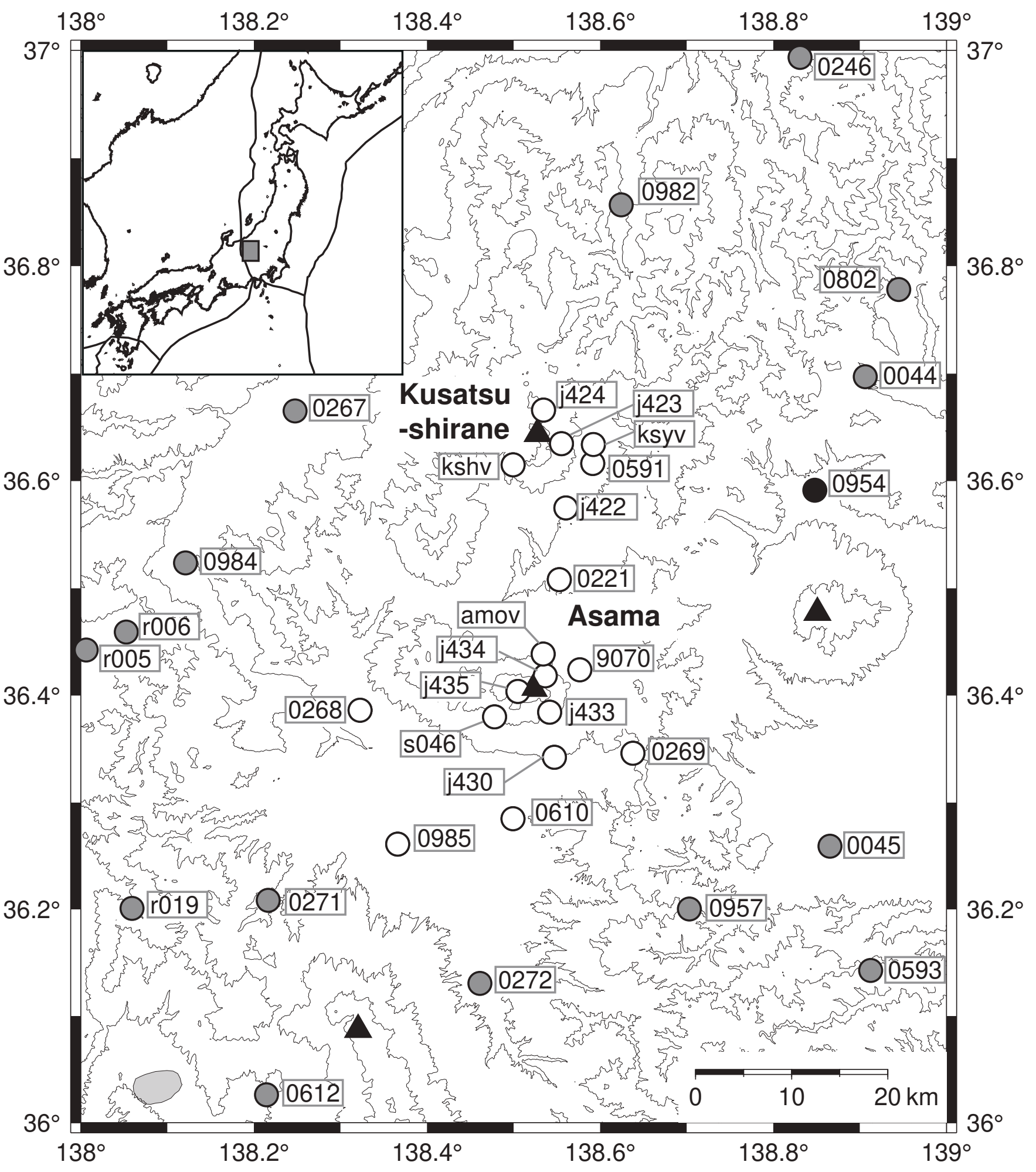


Figure 2

a)

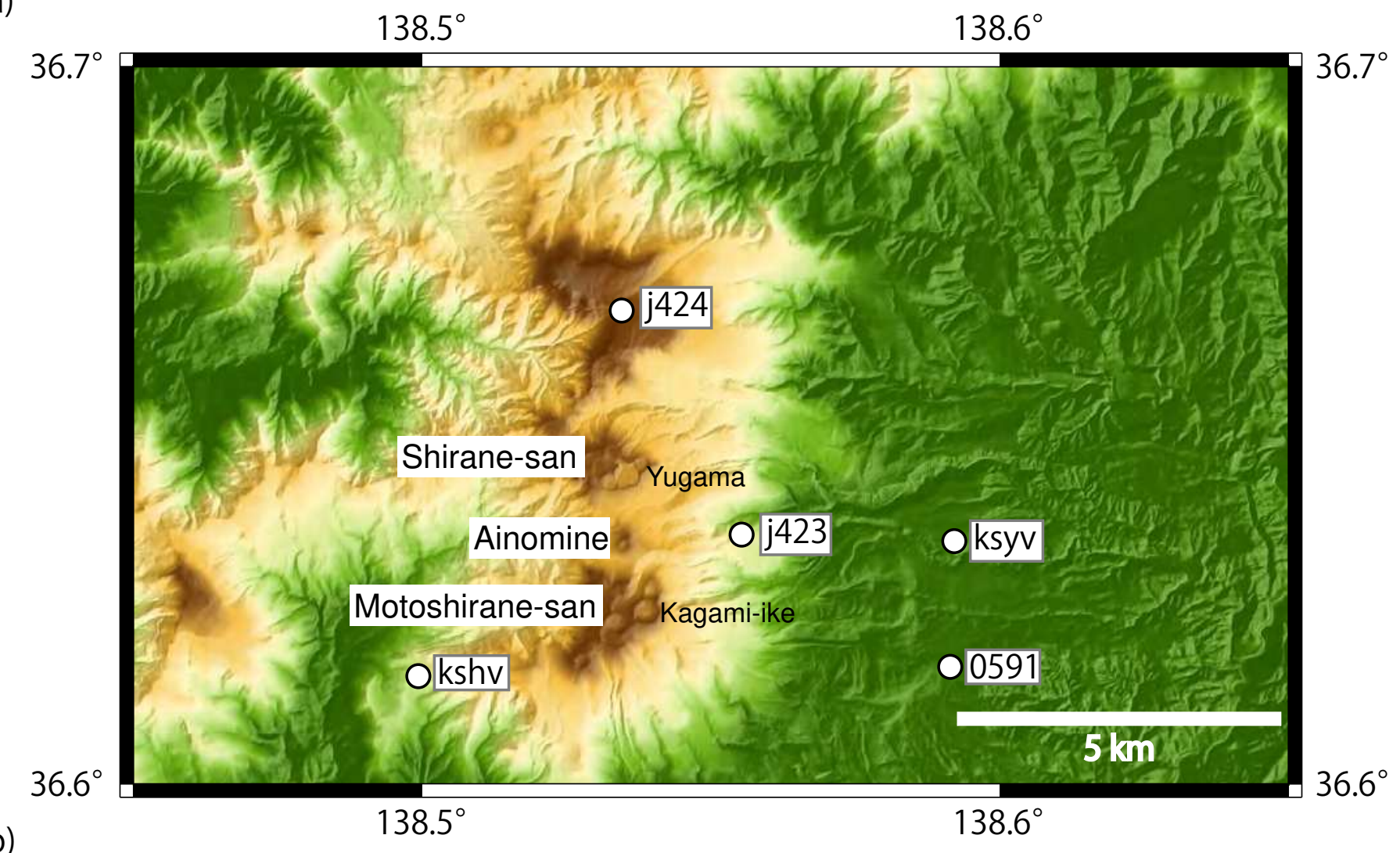

b)

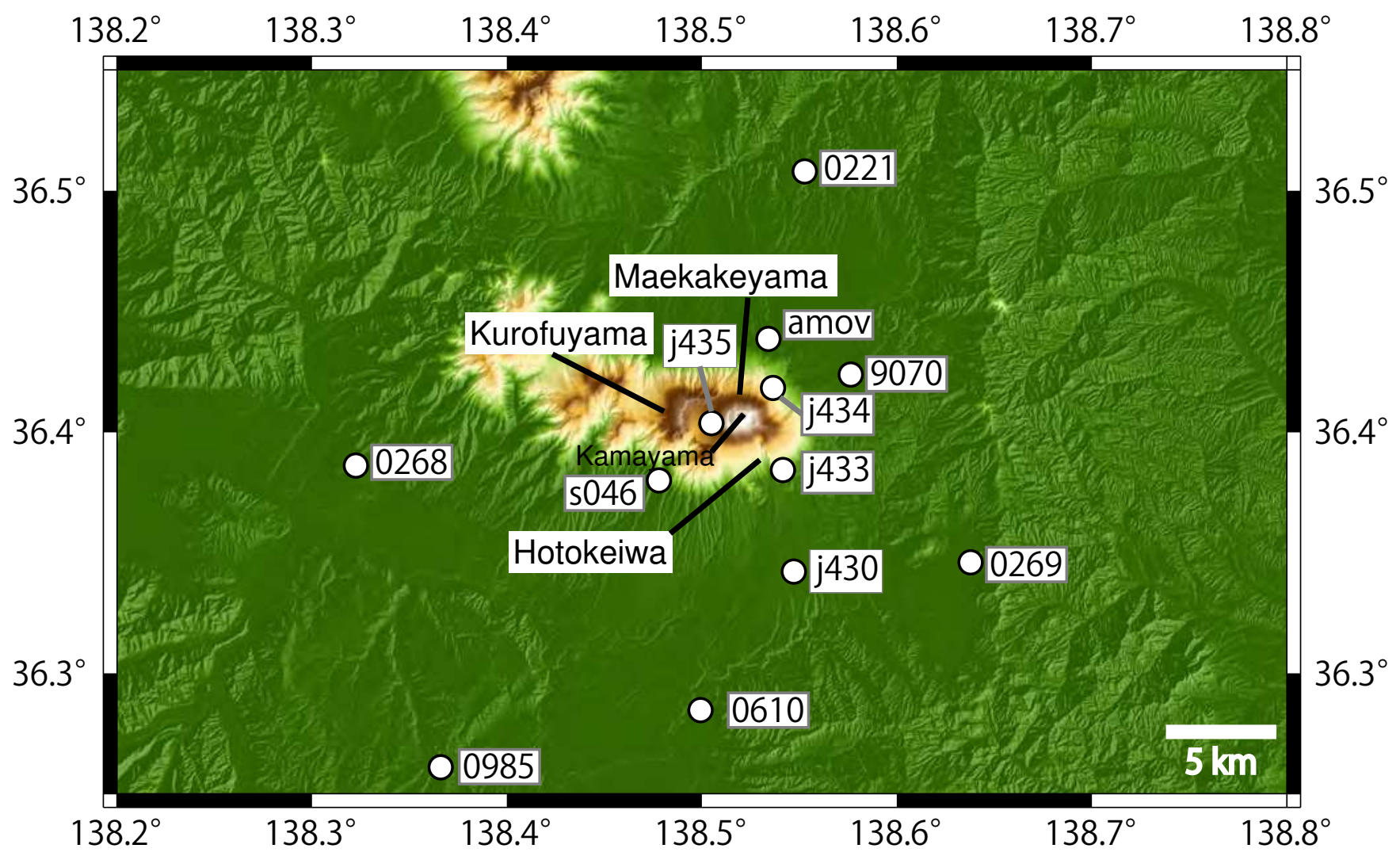


Figure 3

\section{Non volcanic sites}

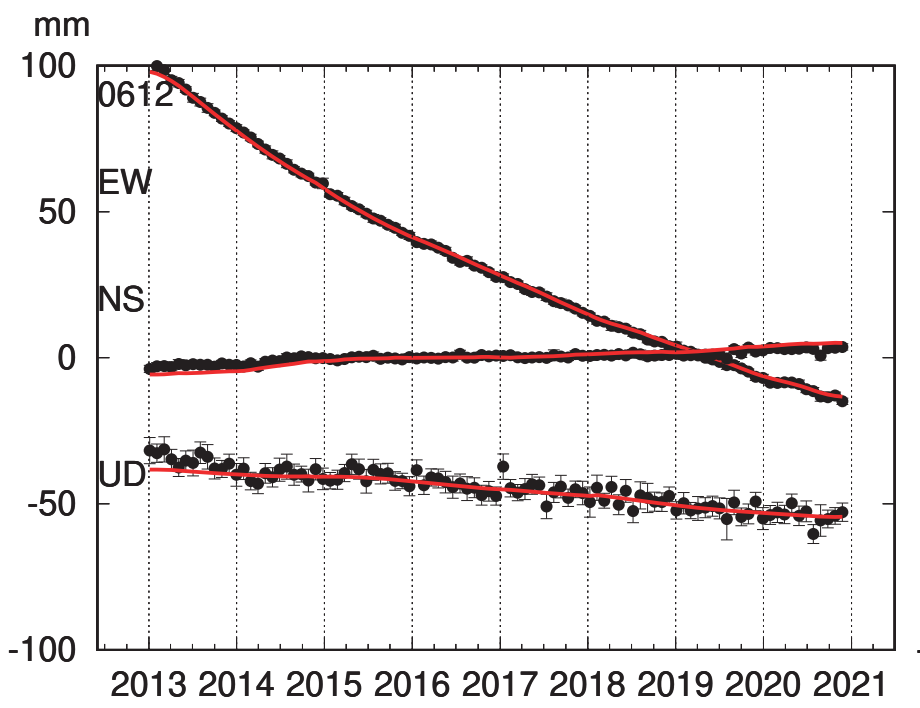

$\mathrm{mm}$

100

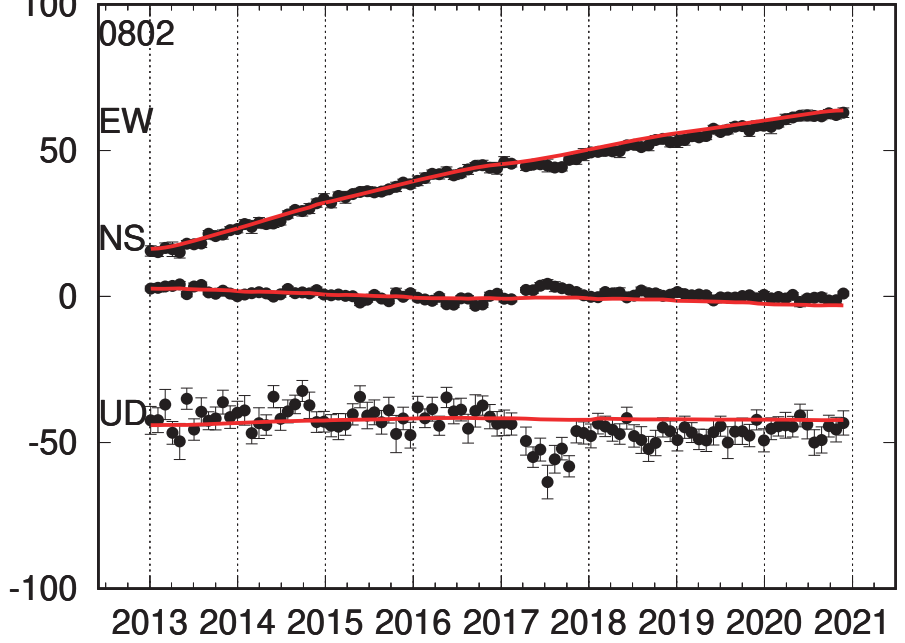

Volcanic sites

$\mathrm{mm}$

100

kshv

50

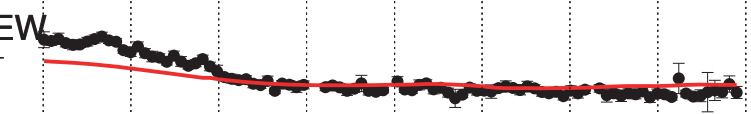

NS

0

$-50$

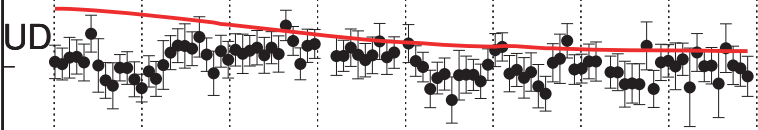

$-100$

201320142015201620172018201920202021 $\mathrm{mm}$

100 j430

50

EW
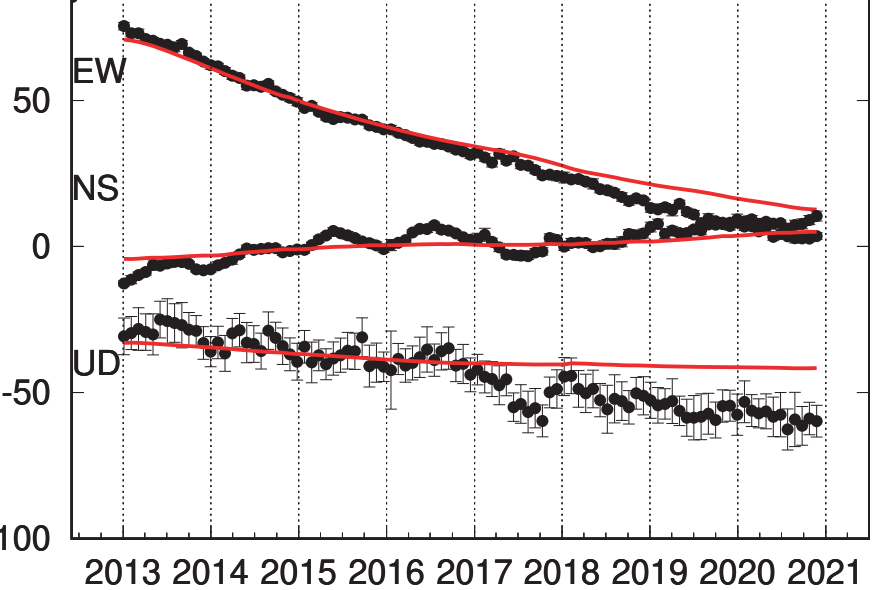
a) Figure 5

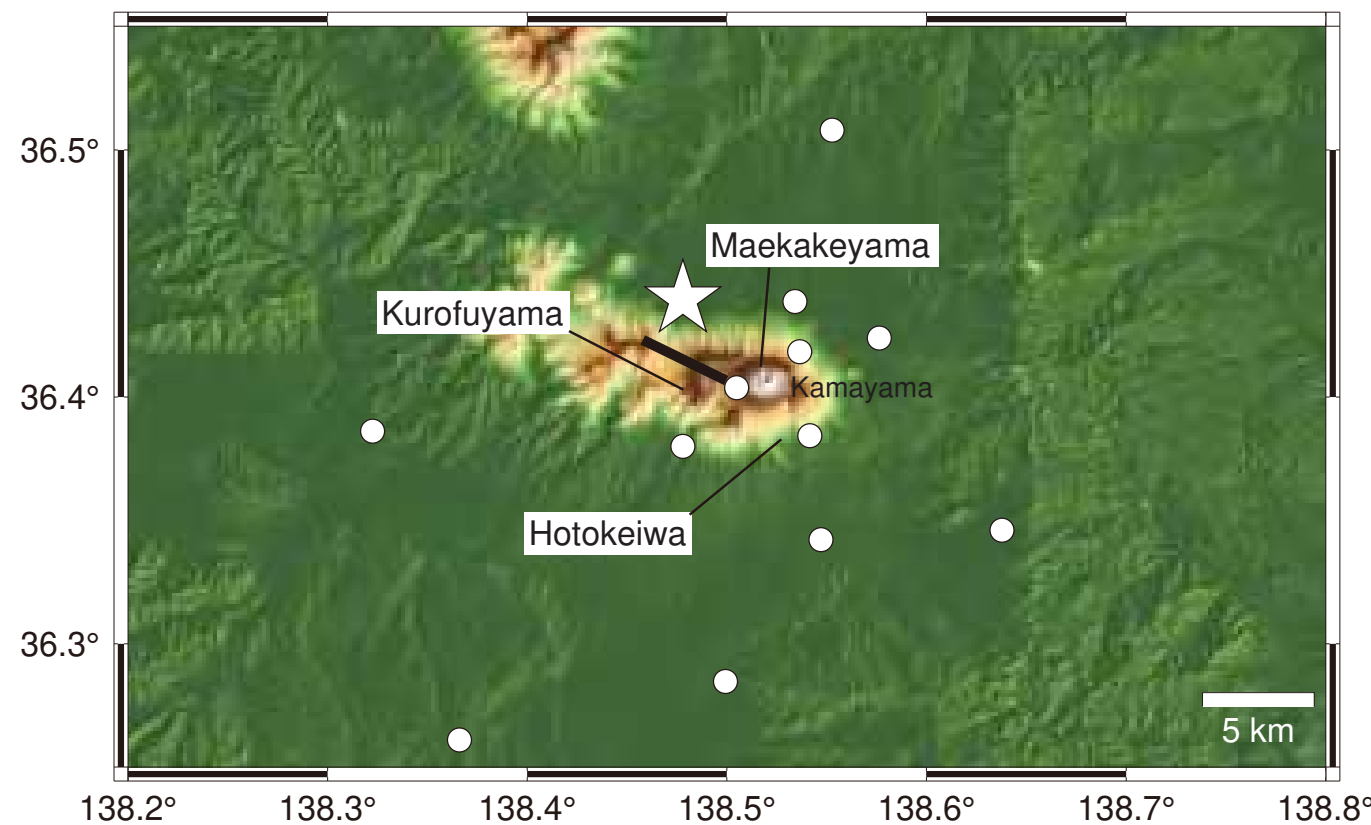

b)
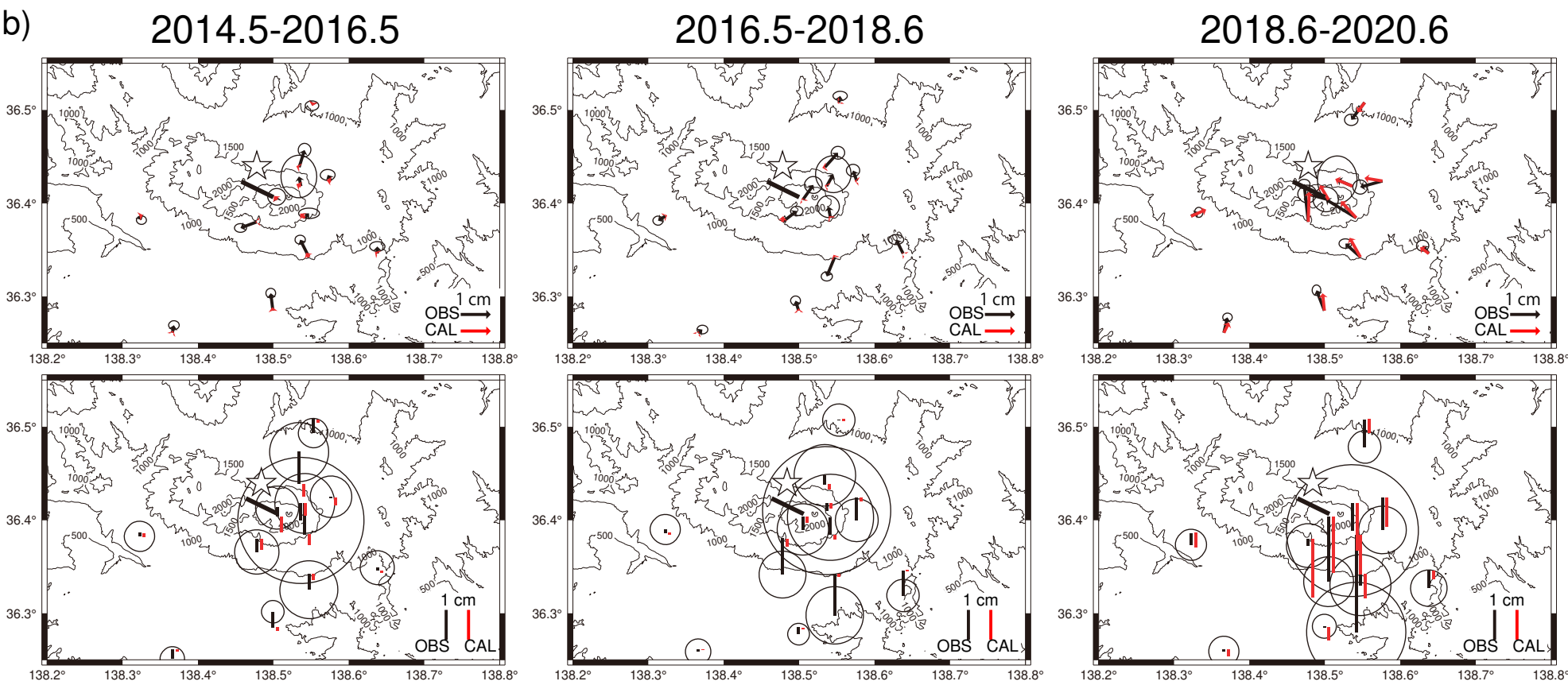
Figure 6
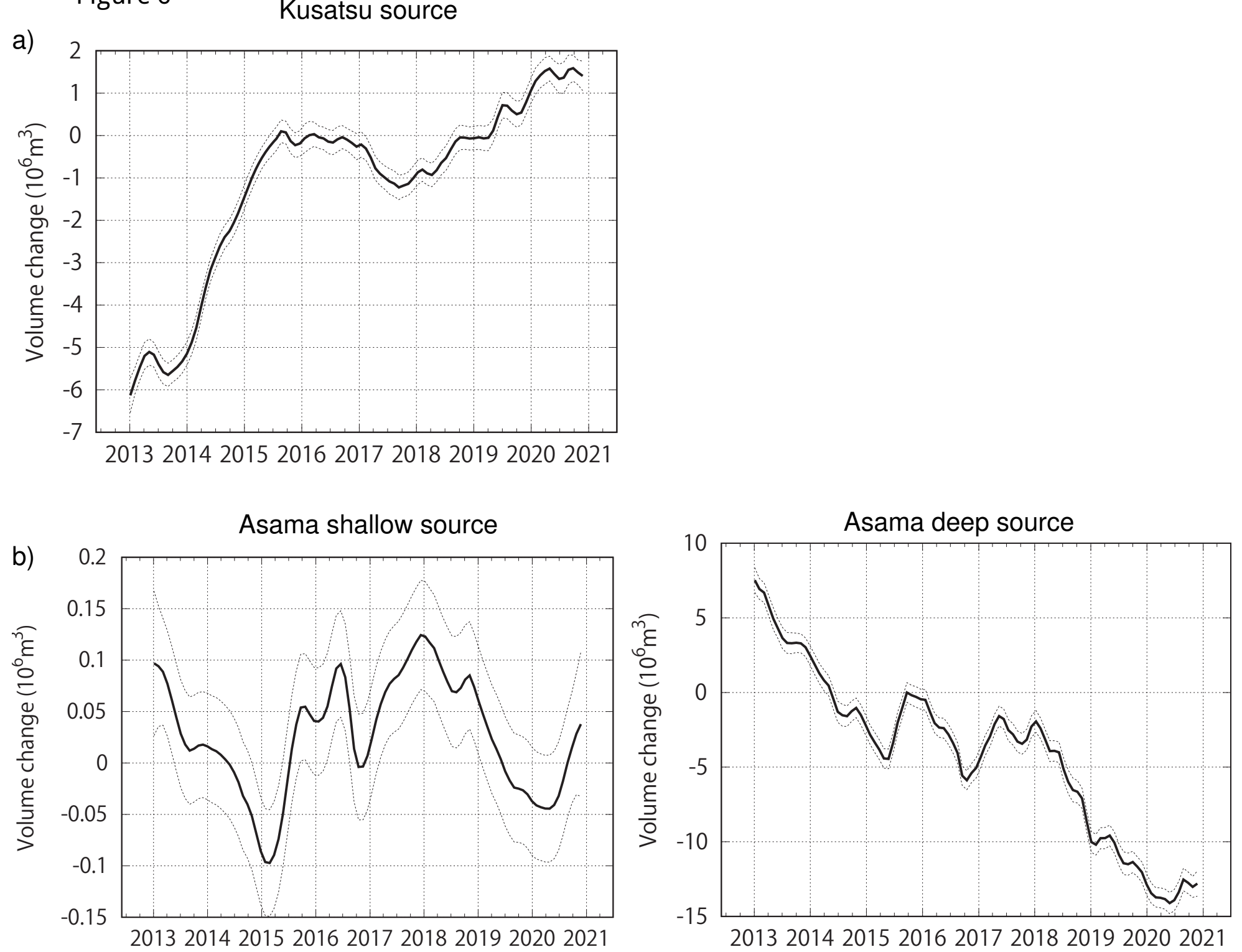
a) ${ }_{\mathrm{mm}} \quad$ Figure 7

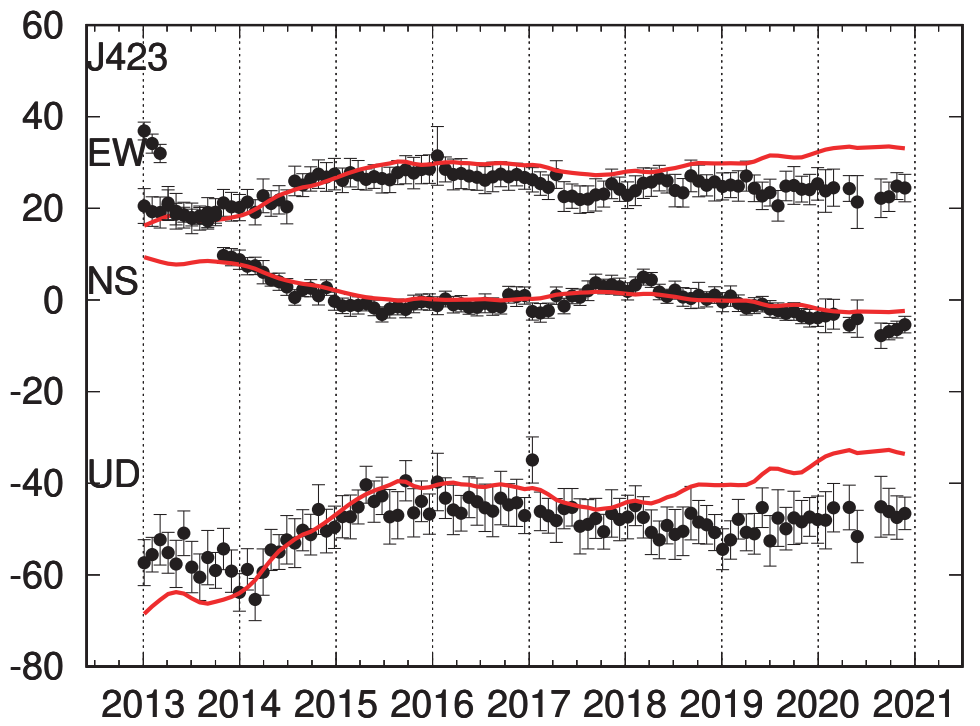

b)

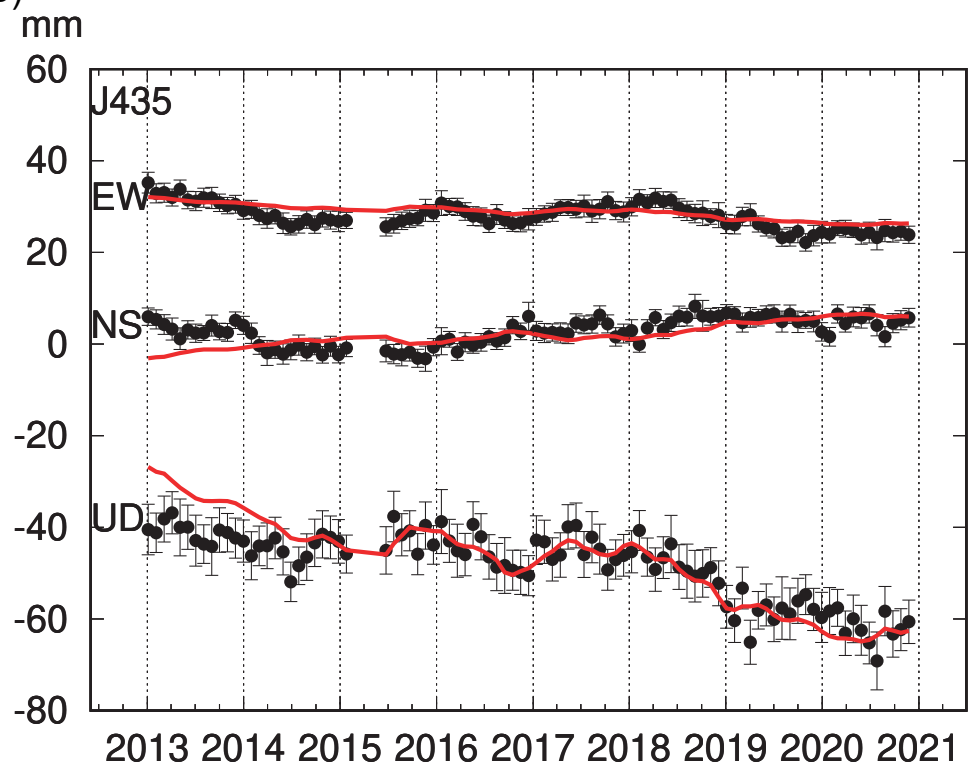

$\mathrm{mm}$

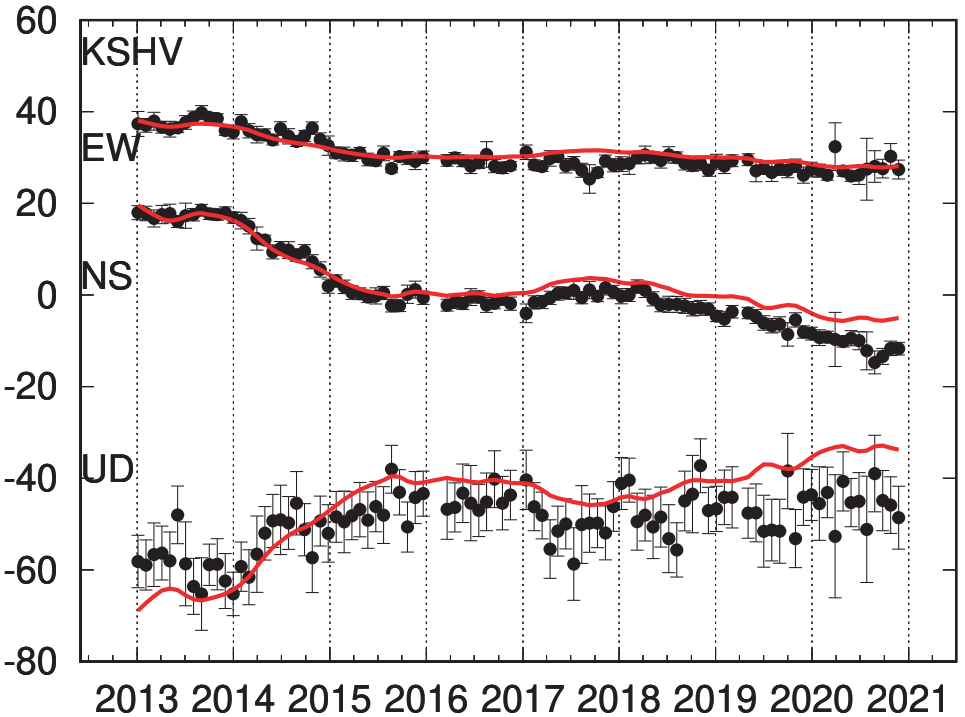

$\mathrm{mm}$

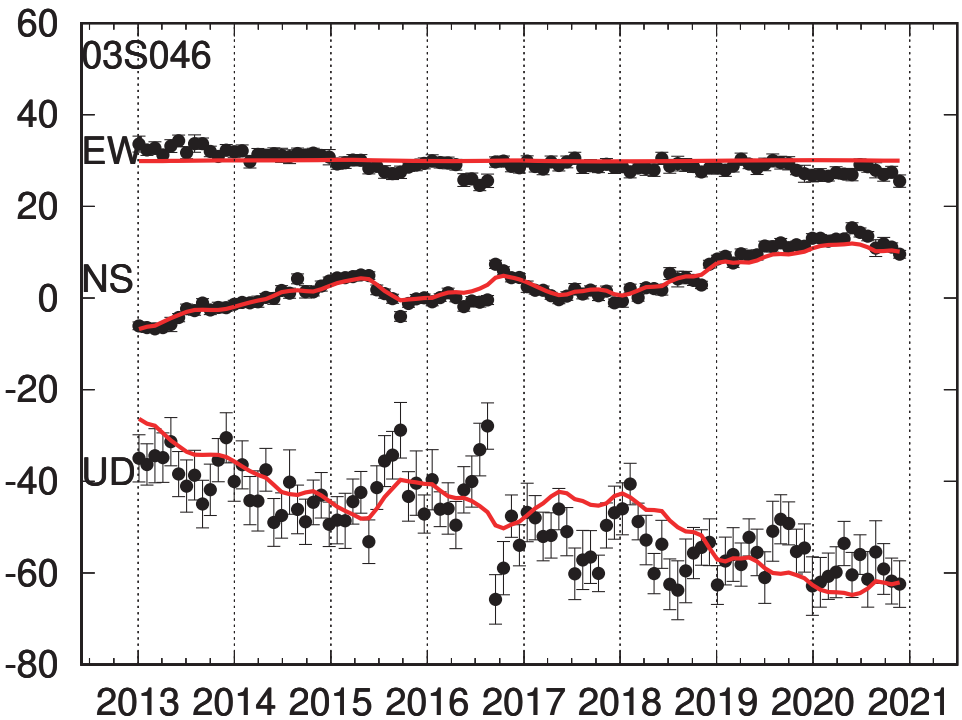



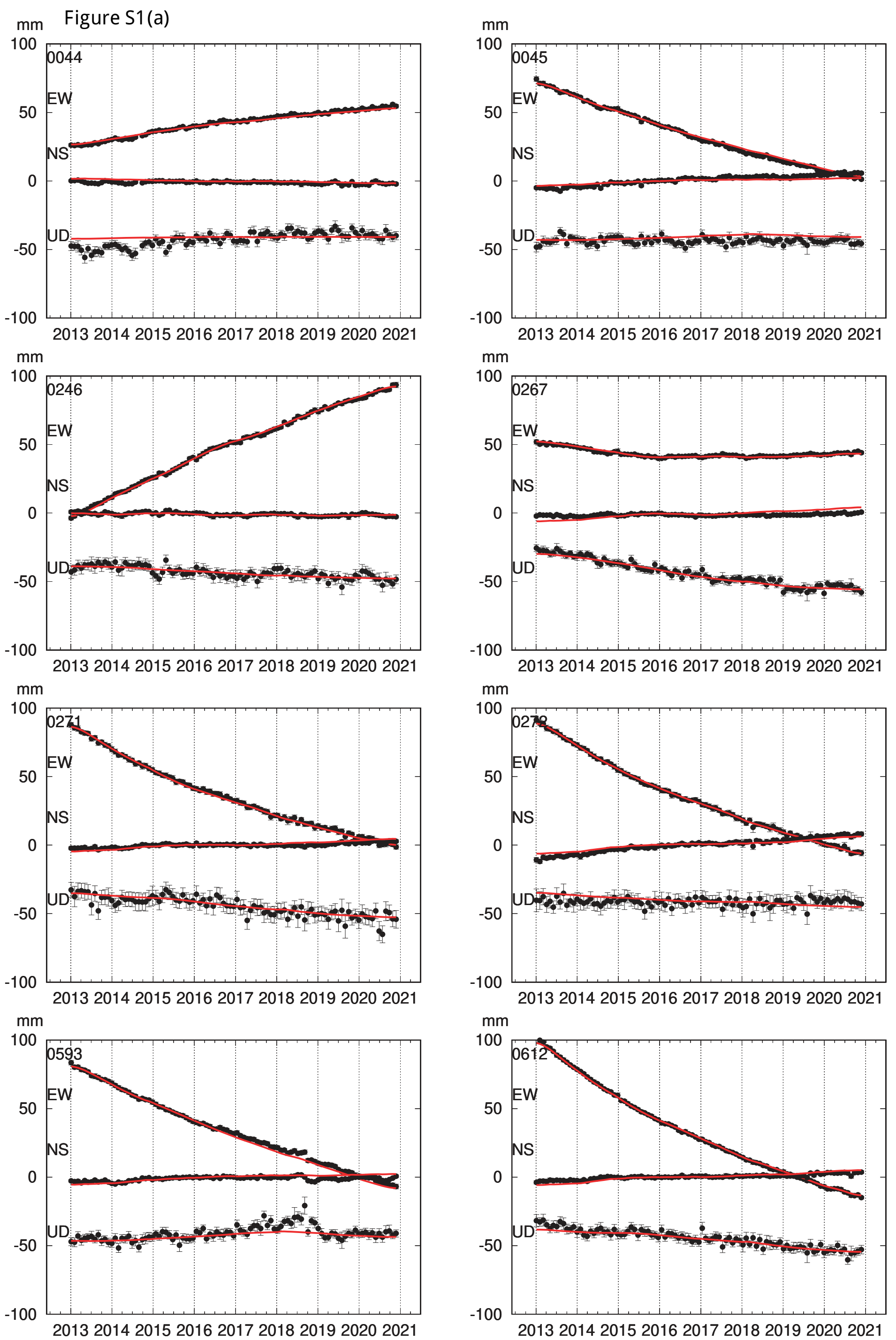

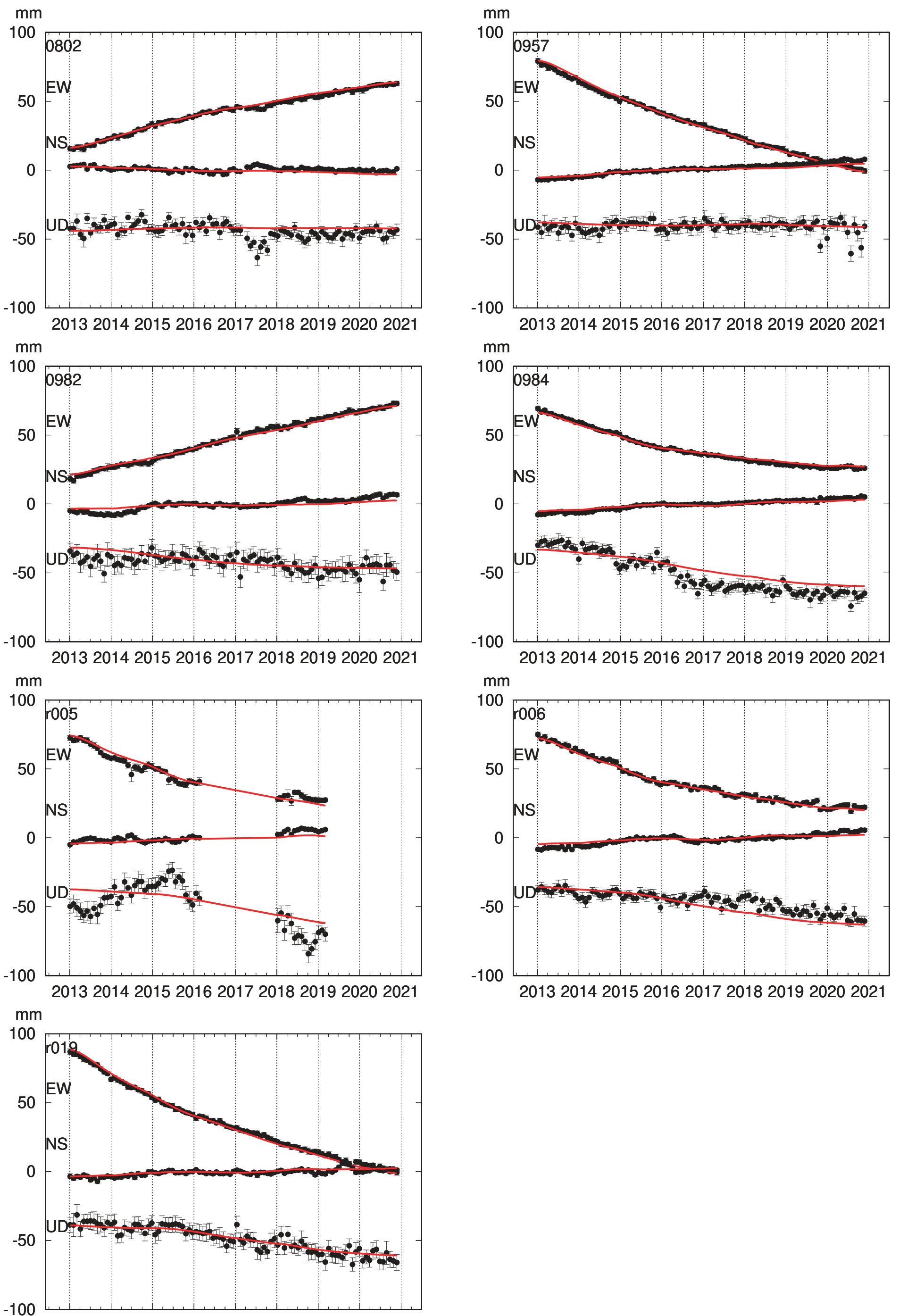
$\mathrm{mm}$

Figure S1 (b)

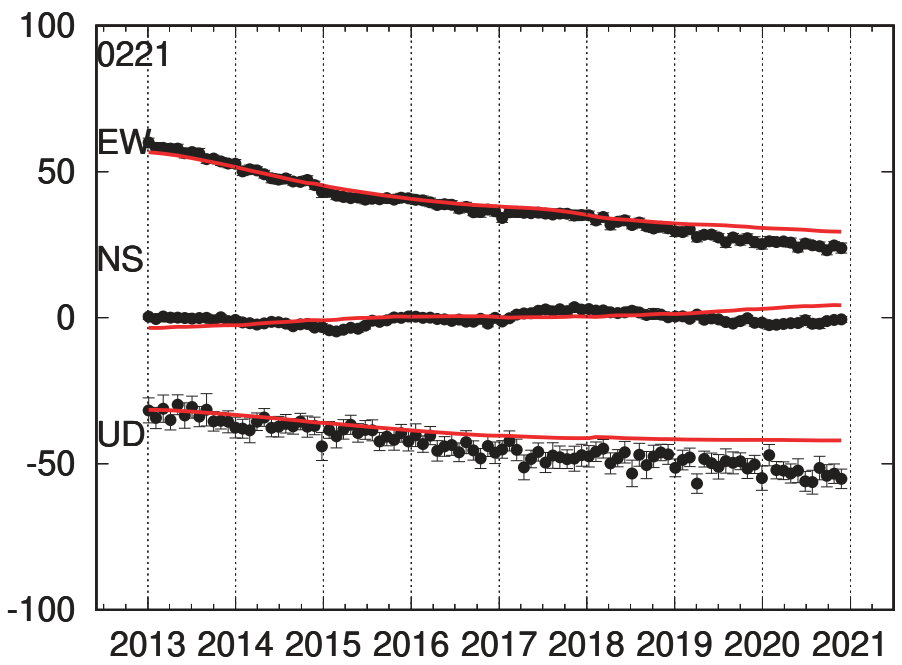

$\mathrm{mm}$

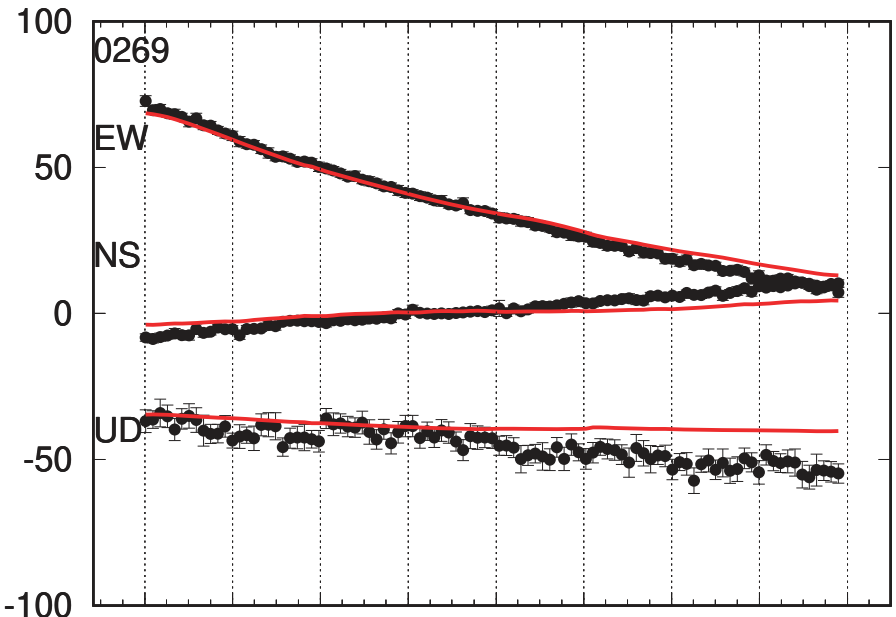

201320142015201620172018201920202021

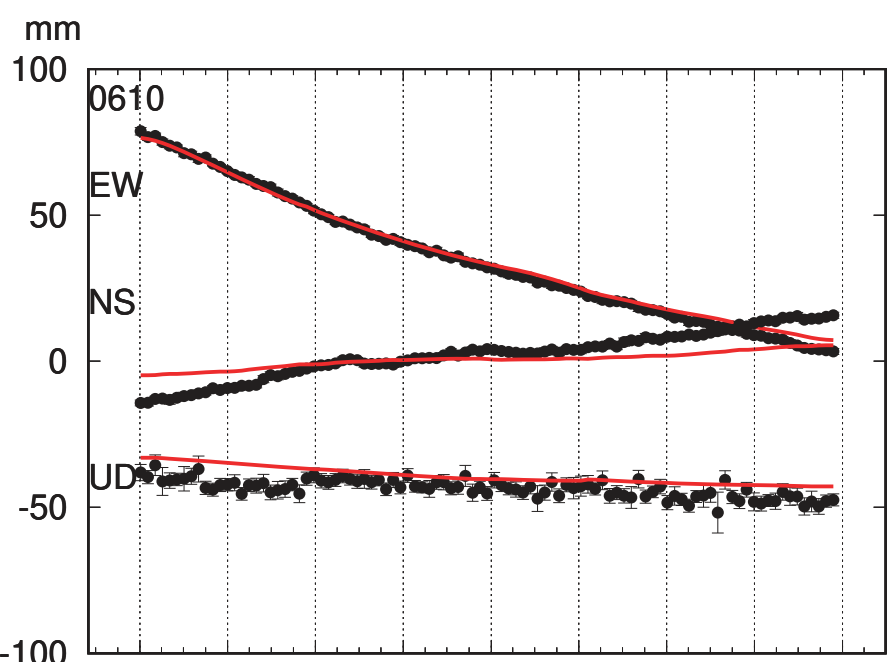

$$
-100
$$

201320142015201620172018201920202021

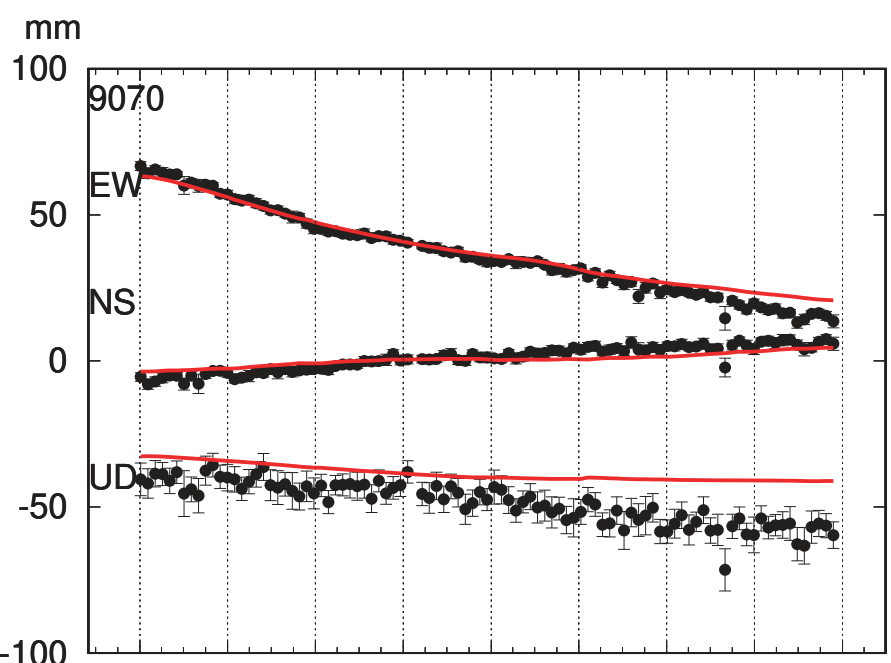

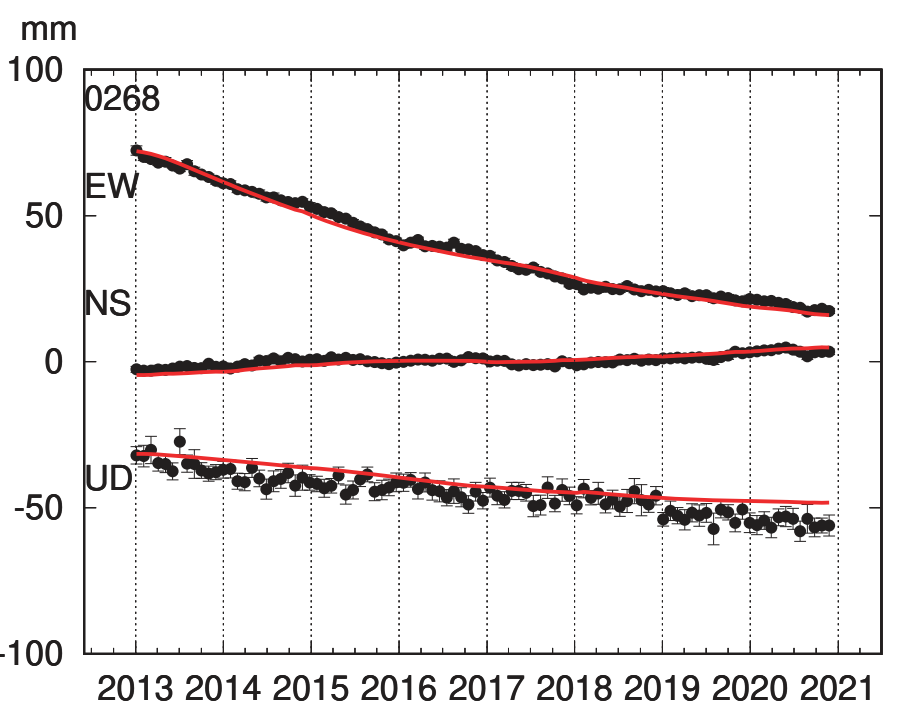

$\mathrm{mm}$

100

50

EW

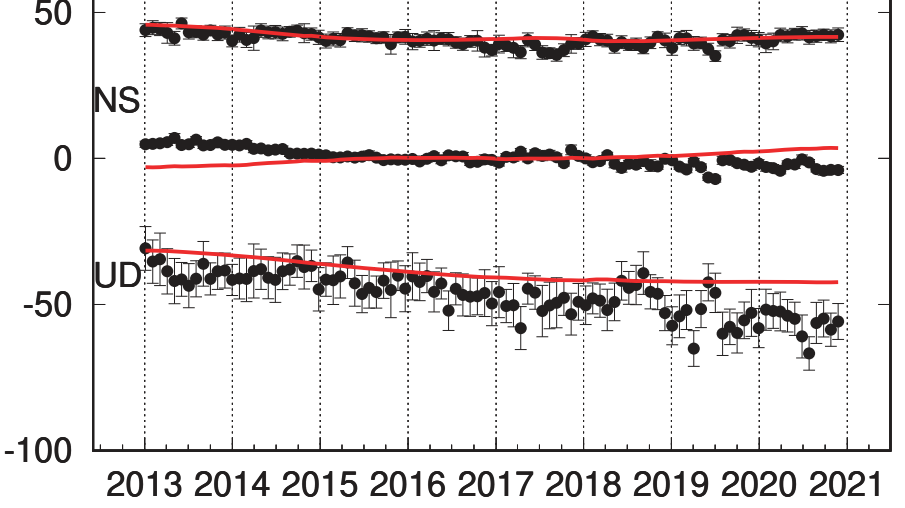

$\mathrm{mm}$

100

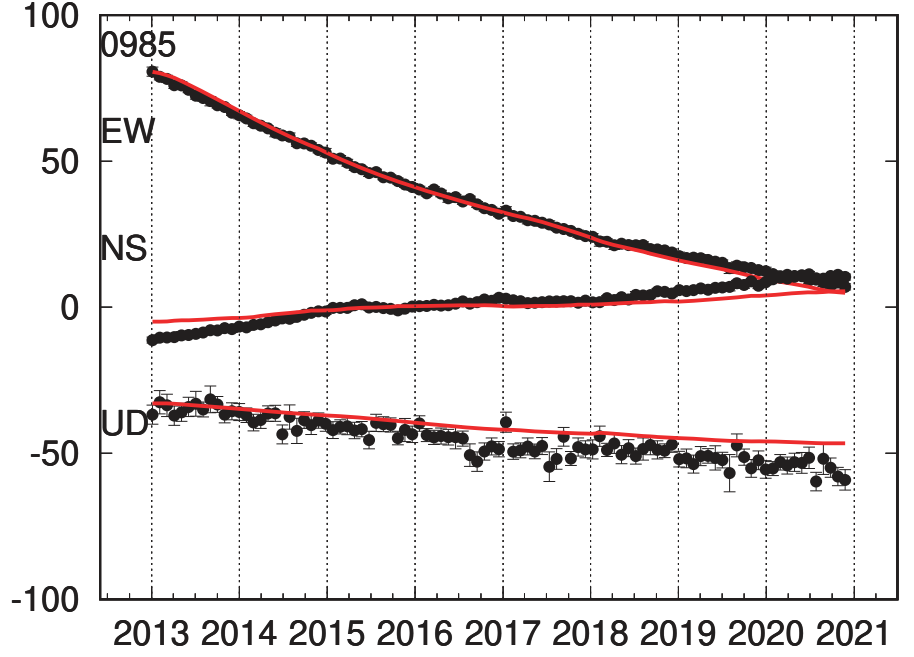

$\mathrm{mm}$

100

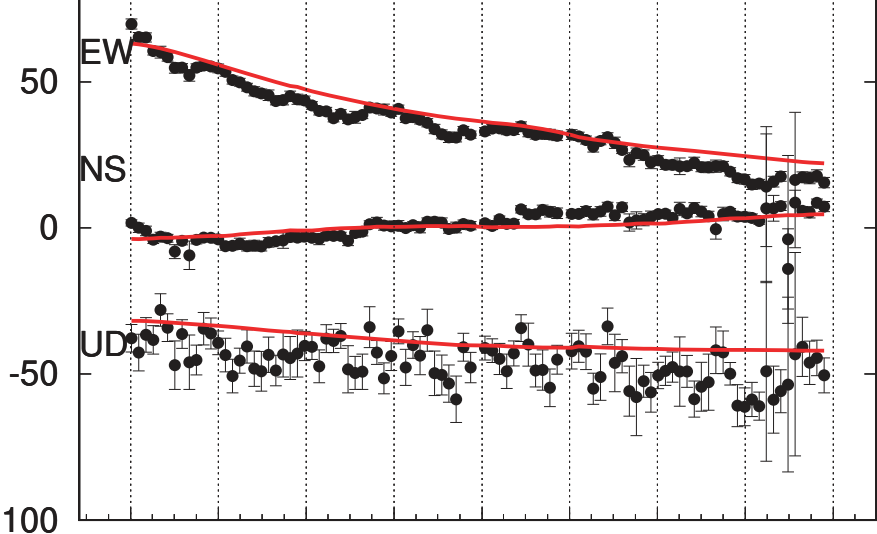

201320142015201620172018201920202021 

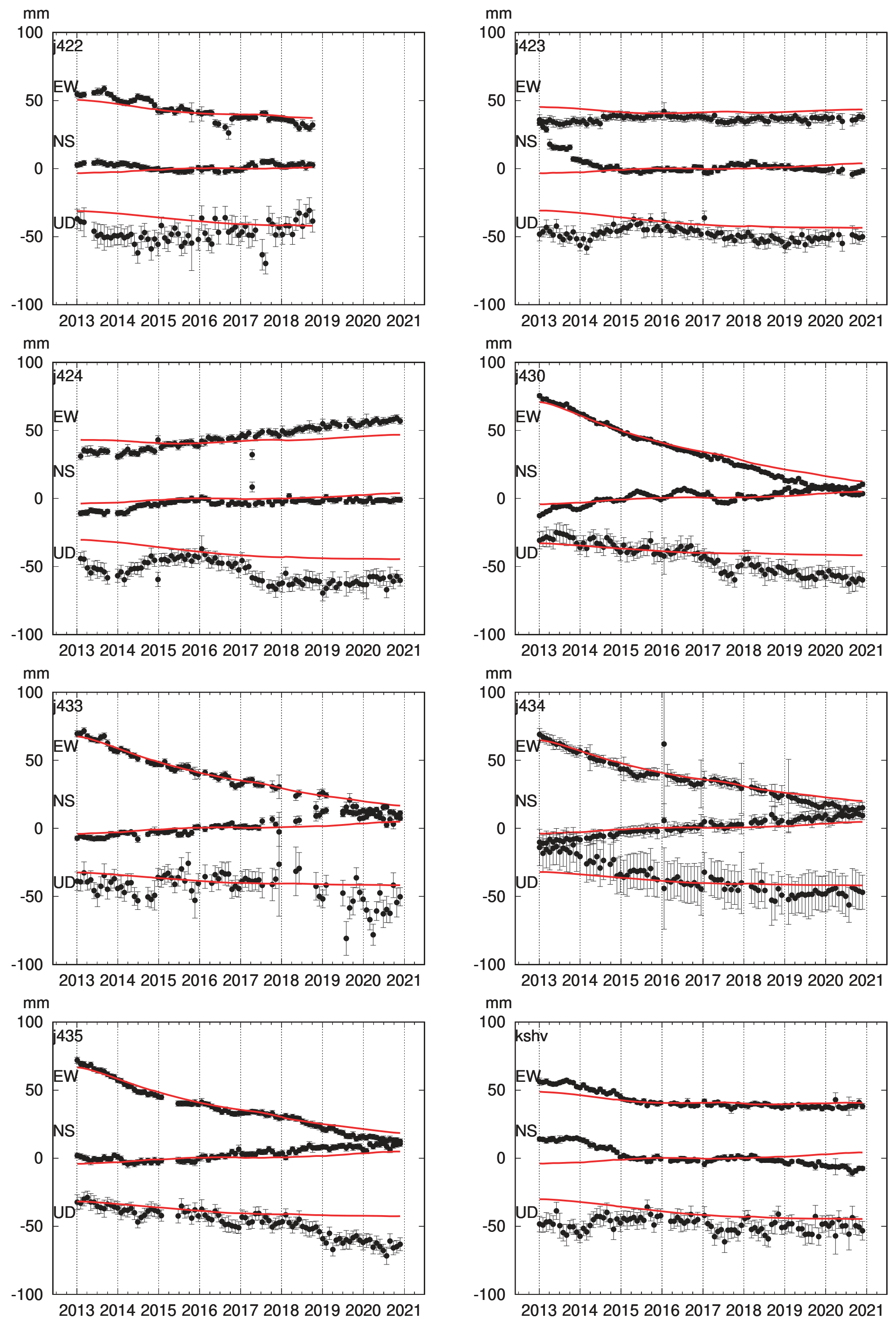

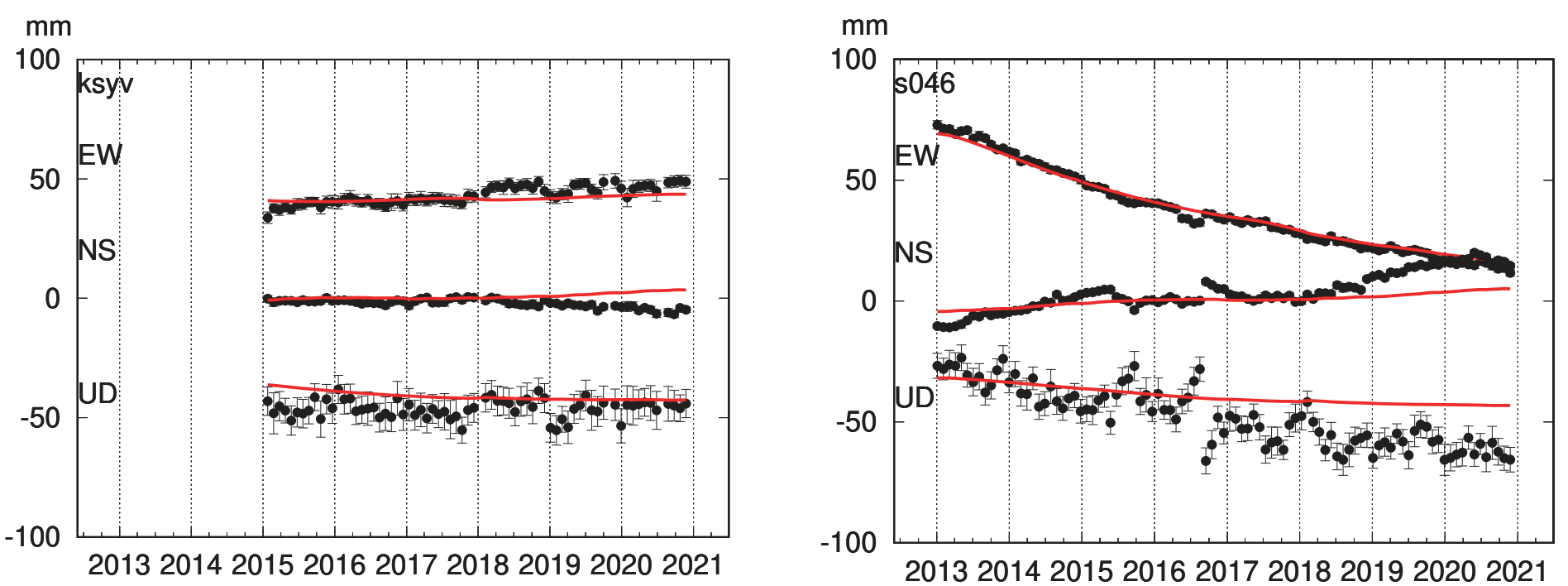

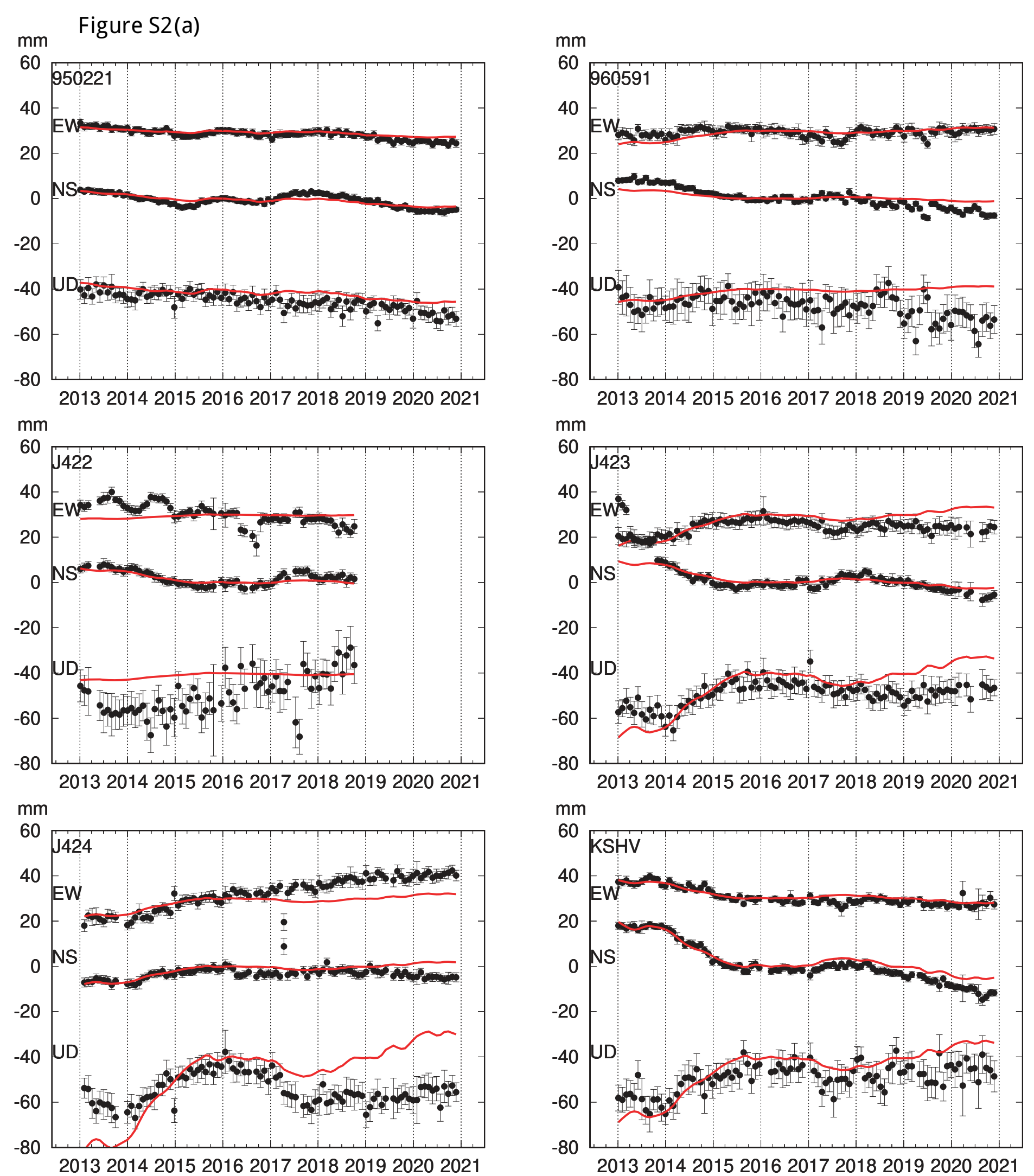

$\mathrm{mm}$

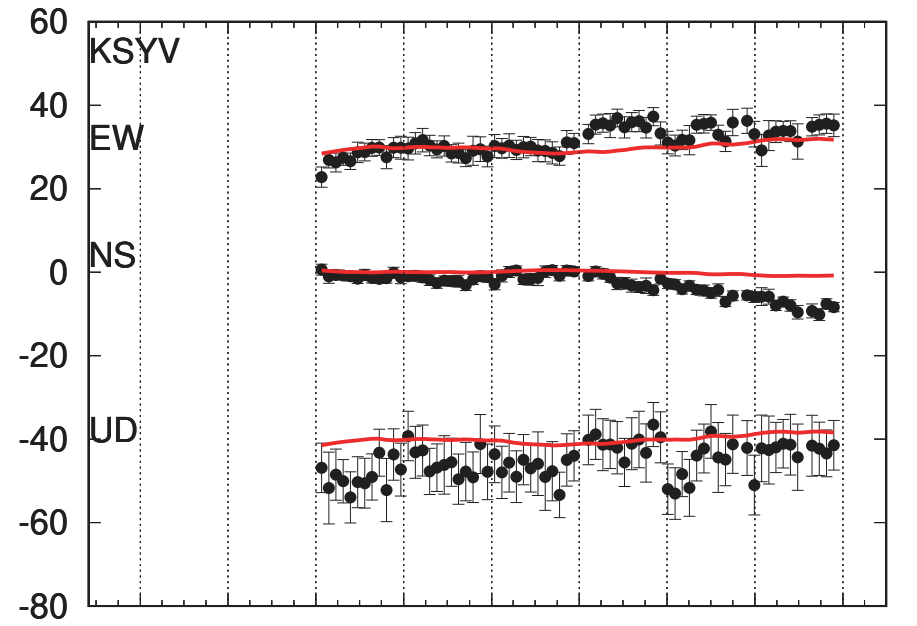
$\mathrm{mm}$

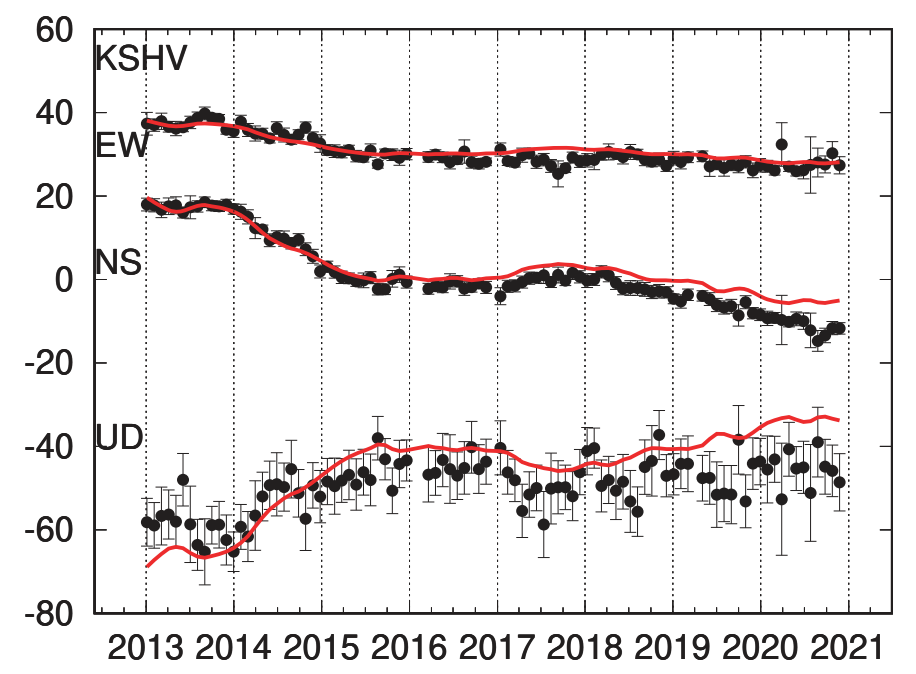


Figure S2(b)

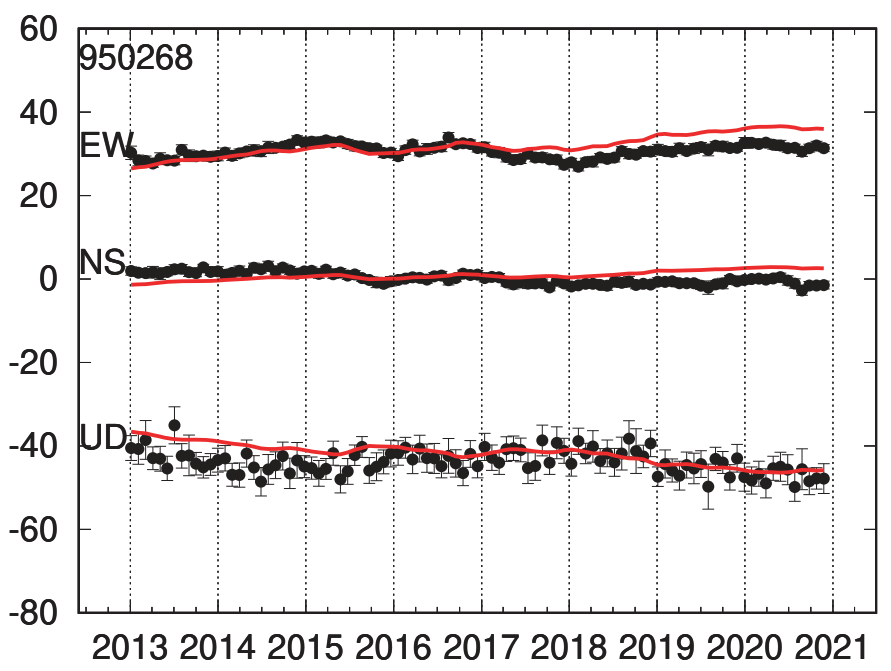

$\mathrm{mm}$

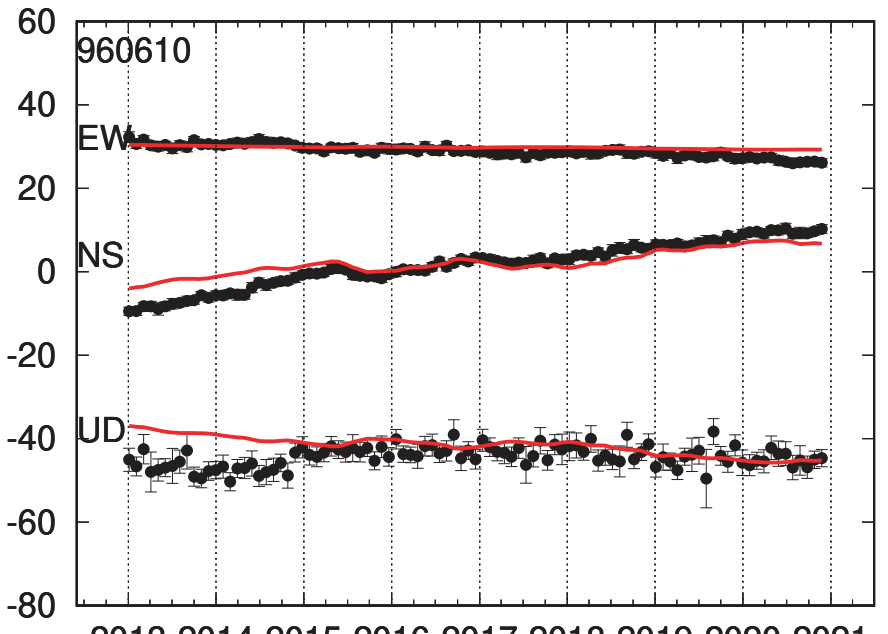

201320142015201620172018201920202021

$\mathrm{mm}$

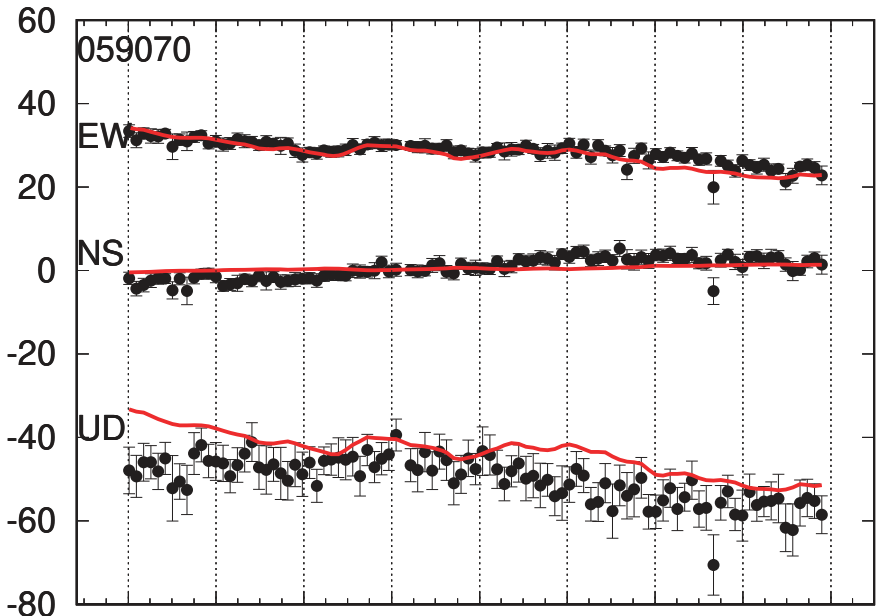

201320142015201620172018201920202021

$\mathrm{mm}$

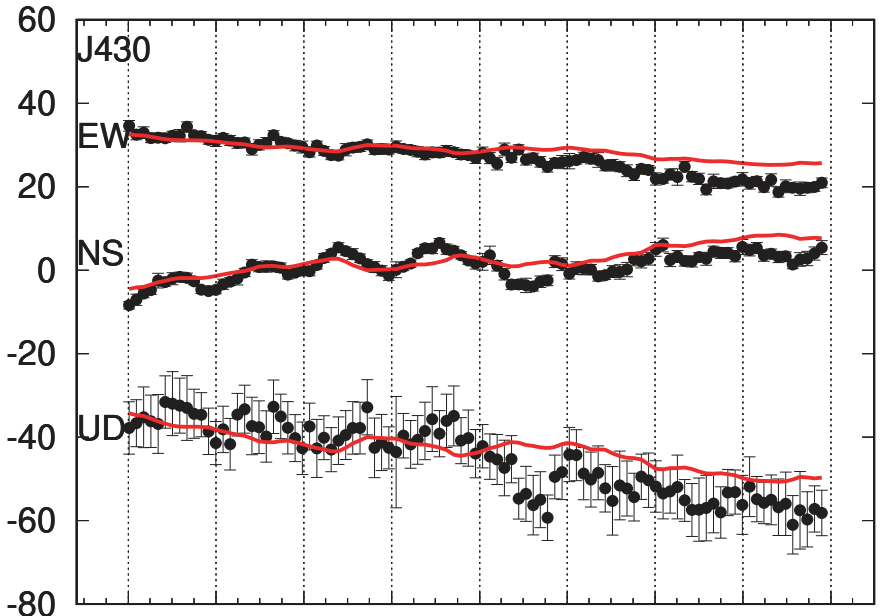

201320142015201620172018201920202021 $\mathrm{mm}$

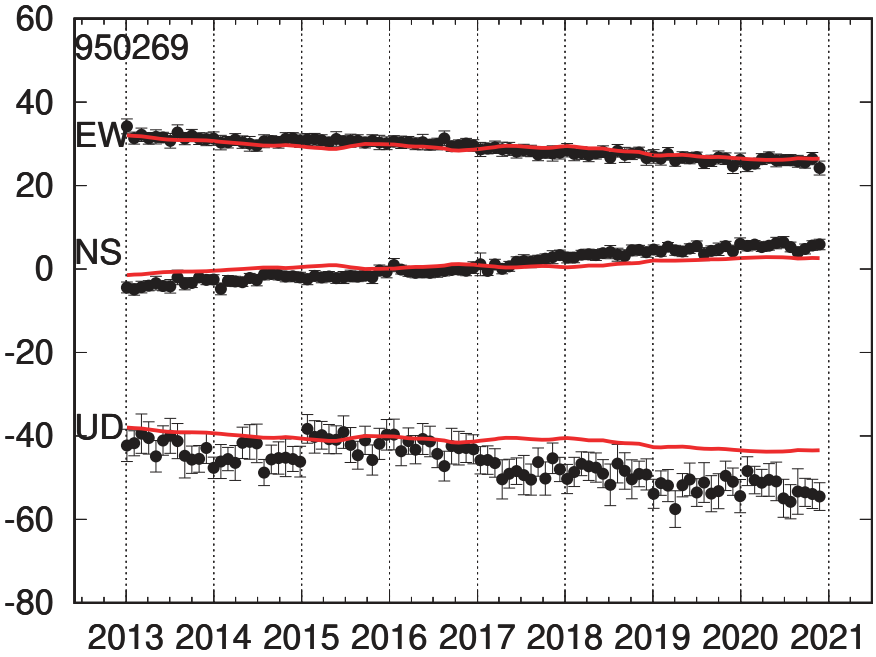
$\mathrm{mm}$

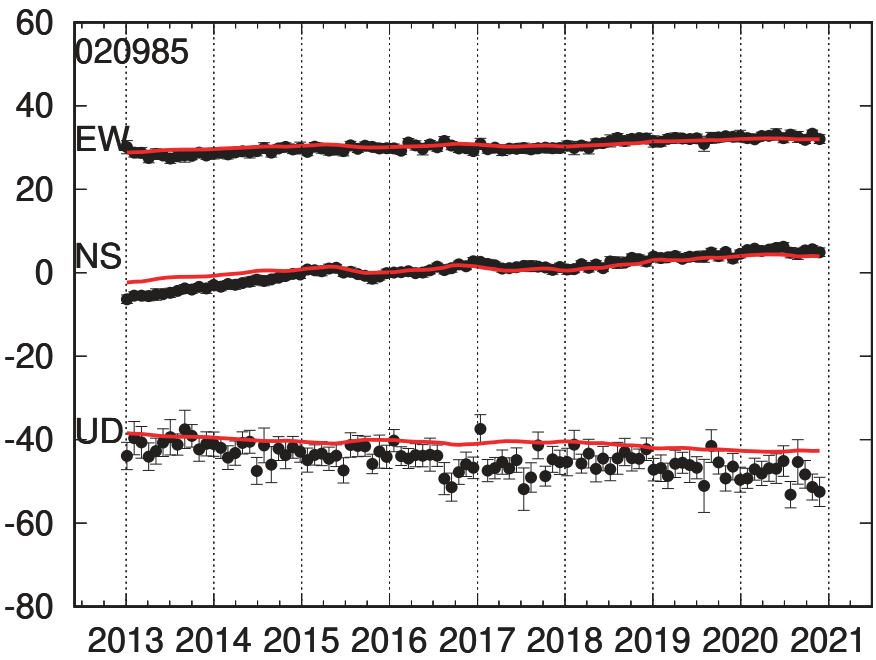
$\mathrm{mm}$

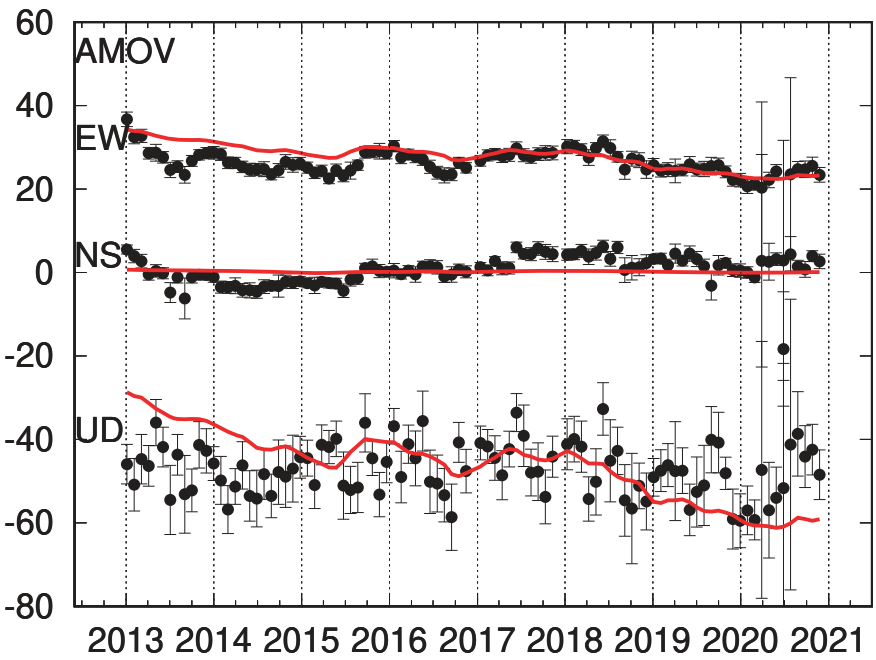
$\mathrm{mm}$

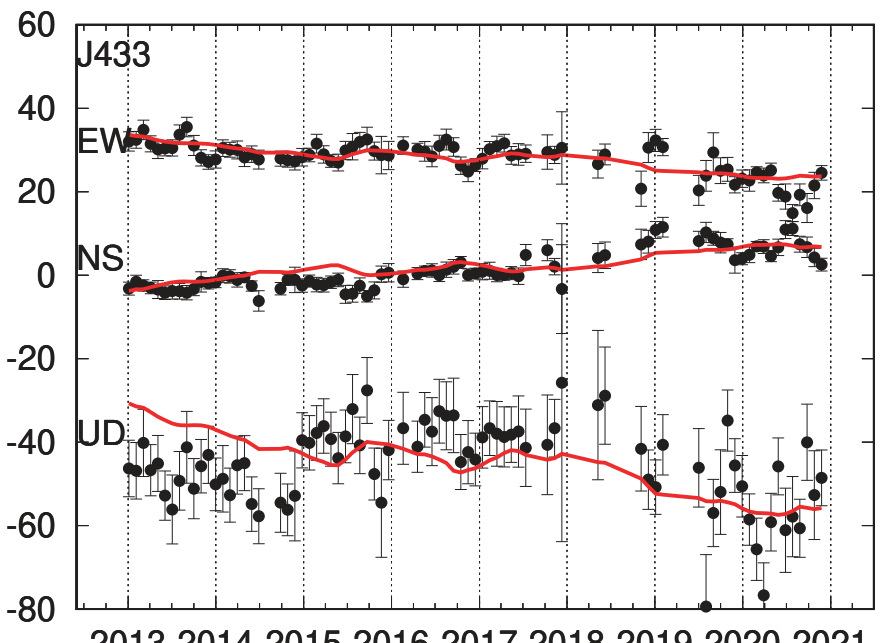



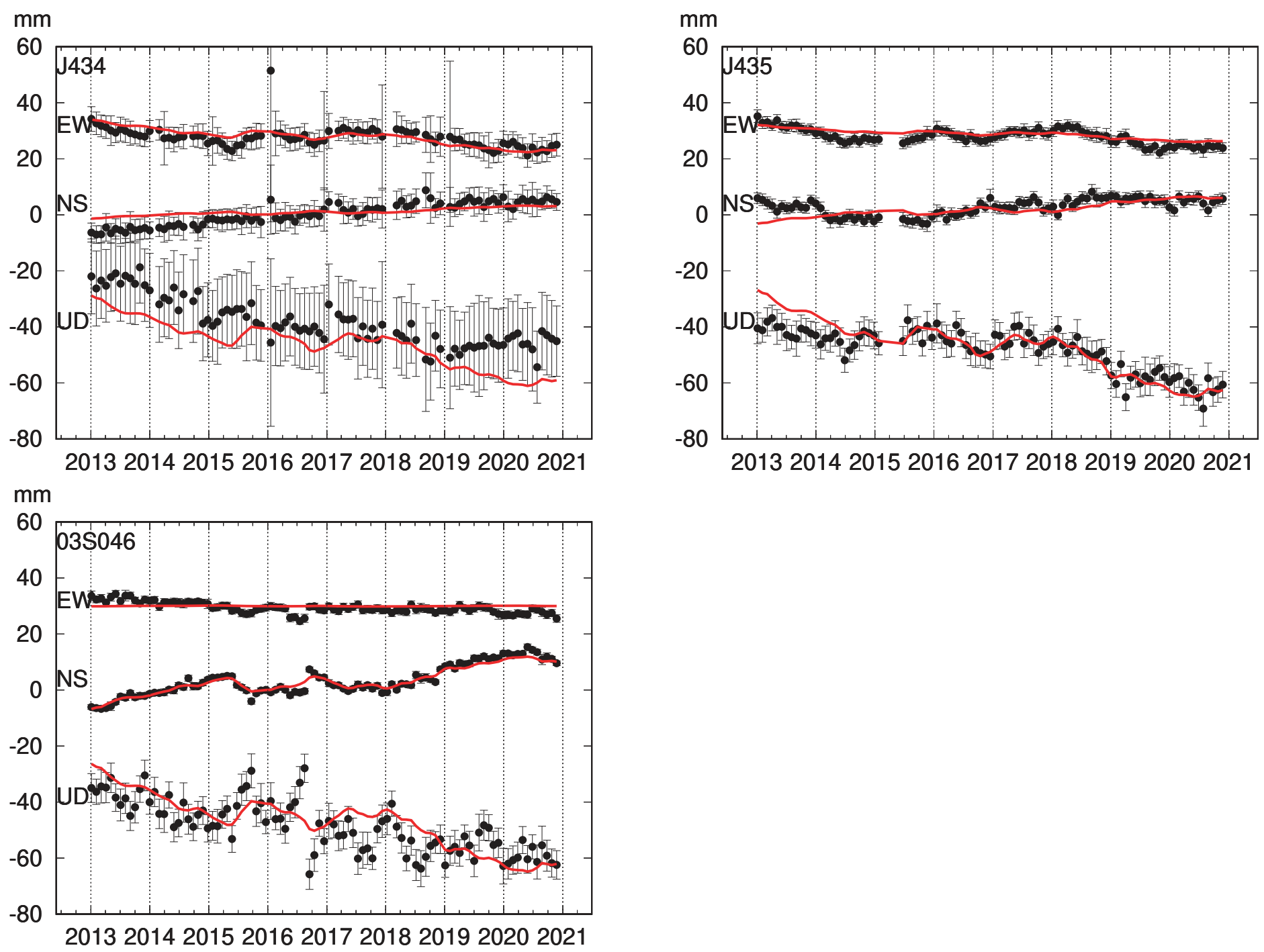
Table S1. Source parameters for coeruptive and posteruptive deformations of Motoshiran e volcano in 2018 after Himematsu et al. (2020). Position of the dislocation source is represented by its top-left.

*Point source

Lon (deg) : Lat (deg)

138.542
$*$ Dislocatio

Lat $($ deg)
36.626

Depth $(\mathrm{km})$ : Volume change $\left(10^{\wedge} 6 \mathrm{~m}^{\wedge} 3\right)$

Lon (deg) : Lat (deg)

: Depth $(\mathrm{km})$ : Length $(\mathrm{km})$ : Width $(\mathrm{km})$ : Strike (deg

) : Dip (deg): $\begin{gathered}: \quad \text { Lake (deg) : slip (m) } \\ 138.539\end{gathered}$

$138.53956:-56.628$

: $-2.0: 0.5$

$: \quad 0.75$

: 105 . 
Table S2. Source parameters for a shallow source under the Yugama crater in the 2014 nrest (Tokyo Institute of Technology, 2016\}. Position of the opening dike is represent ed by its top-left.

Lon (deg) : Lat (deg)

Lon $(\operatorname{deg}) \quad: \quad$ Lat
$1 \quad \operatorname{Dip}(\operatorname{deg}): \operatorname{sip}(\mathrm{m})$
138.535

: Depth $(\mathrm{km})$ : Length $(\mathrm{km})$ : Width $(\mathrm{km})$ : Strike (deg

$138.535:: 36.644$

$=-1.2: 0.48$

$: \quad 0.24$

: 47 . 
Figures

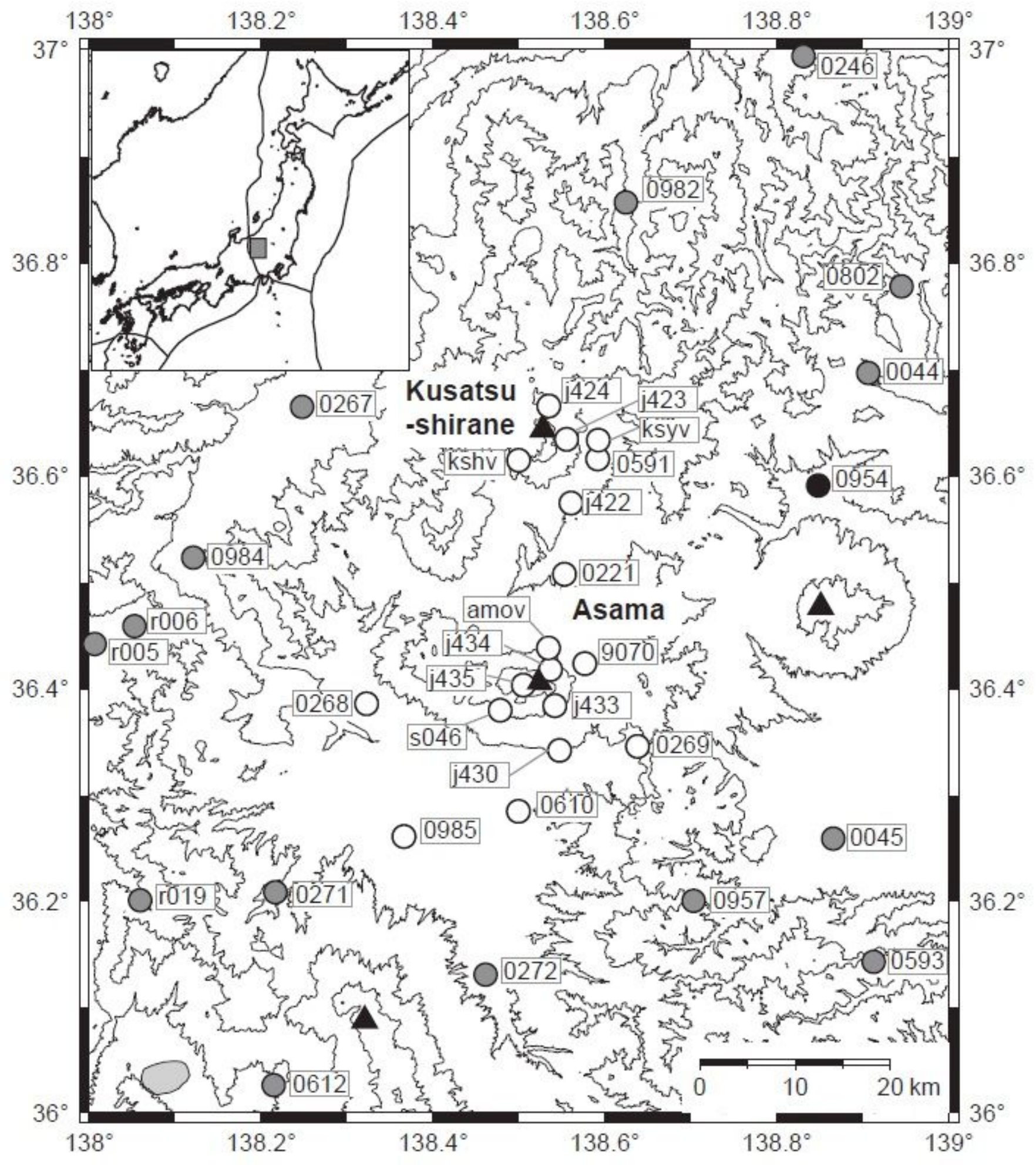

Figure 1

Location of study area and distribution of observation sites. Location of studied area and distribution of observation sites. Inlet shows study area. Active volcanoes are shown as triangles. Circles represent 
GNSS sites used in study. Grey circles are those more than $20 \mathrm{~km}$ away from the Kusatsu-Shirane and Asama volcanoes and used in estimation of parameters representing tectonic deformations.

a)

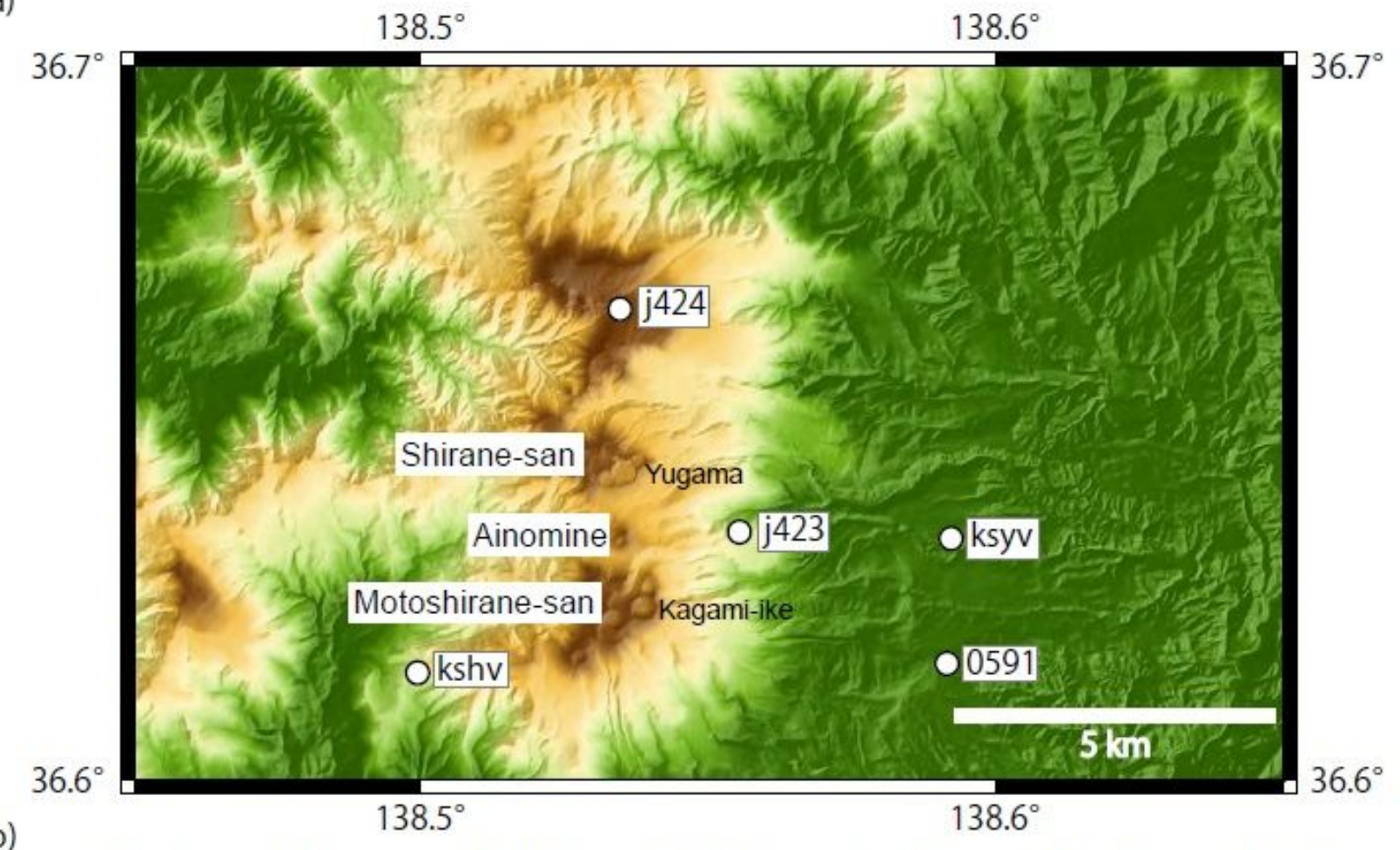

b)

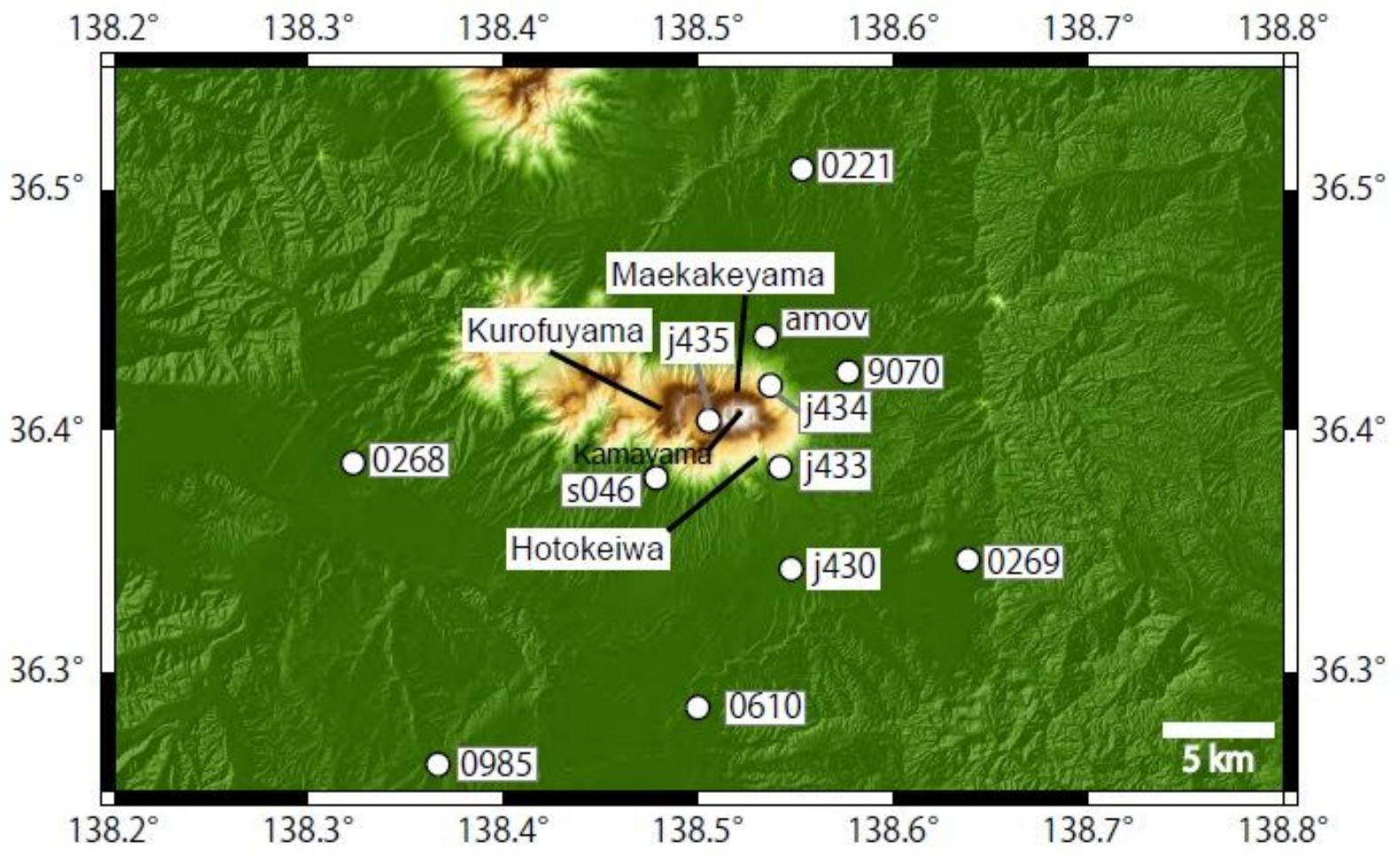

Figure 2

Enlarged maps around Kusatsu-Shirane and Asama volcanoes. Enlarged maps around a) KusatsuShirane volcano, and b) Asama volcano. 

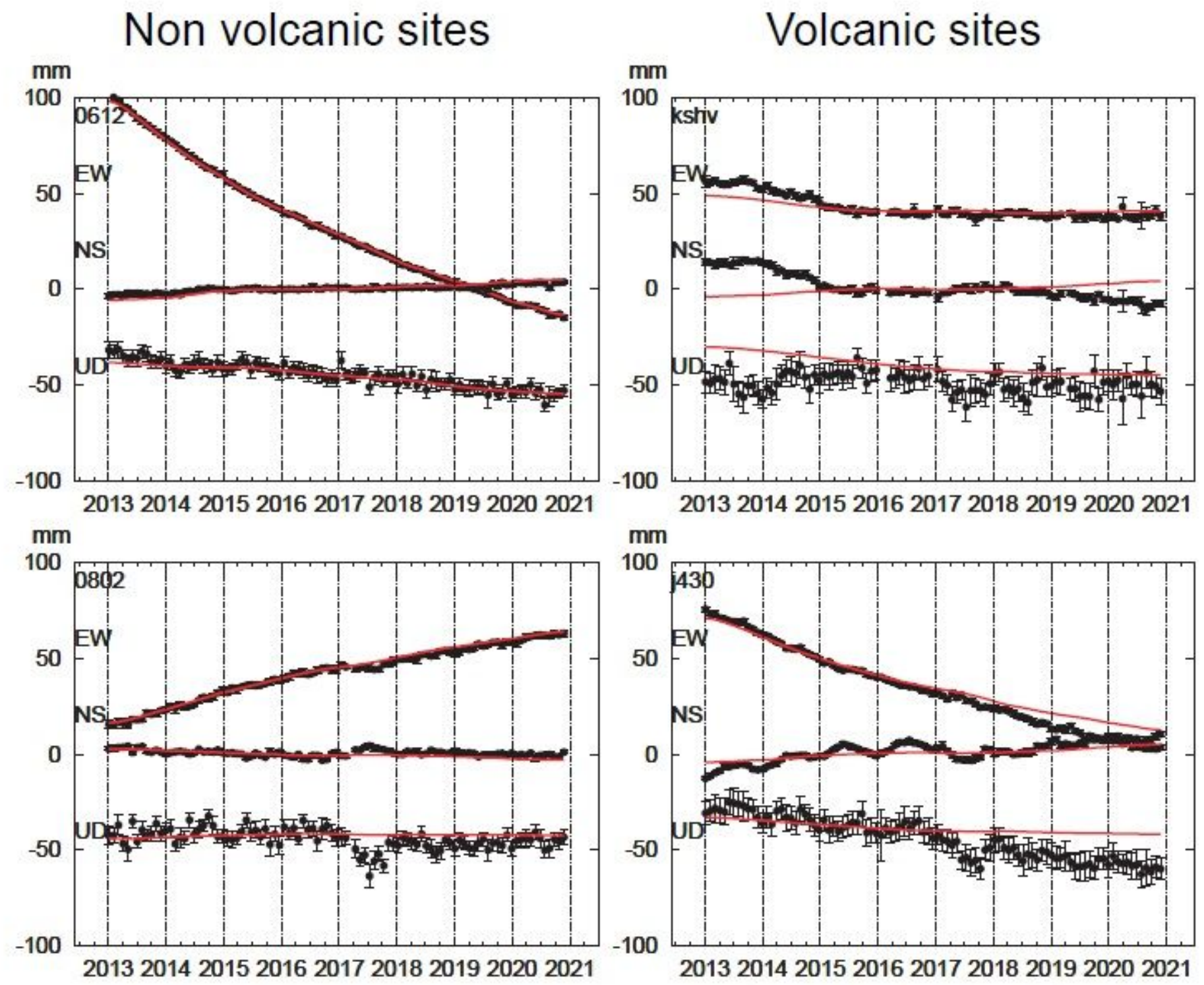

\section{Figure 3}

GNSS coordinate time series and estimated tectonic deformations at selected sites. GNSS coordinate time series and estimated tectonic deformations at selected sites. Black circles denote GNSS coordinate time series and red lines represent tectonic deformations estimated using equation (1). Error bars represent 1 sigma observation errors. Complete GNSS coordinate time series are given in Figures S1(a) and $\mathrm{S} 1(\mathrm{~b})$. 


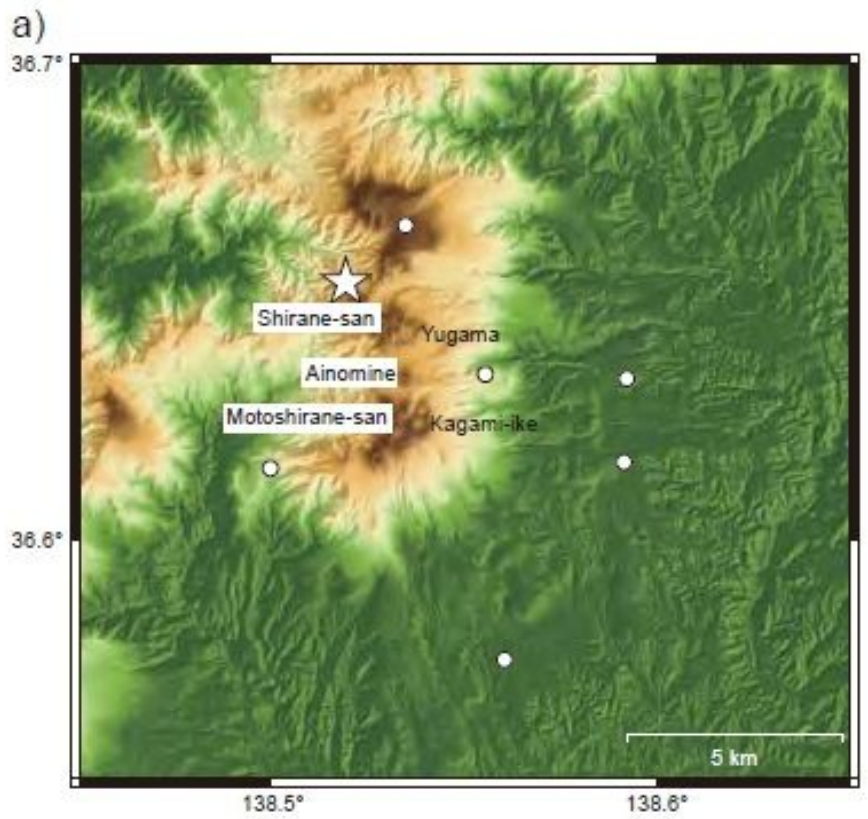

b)
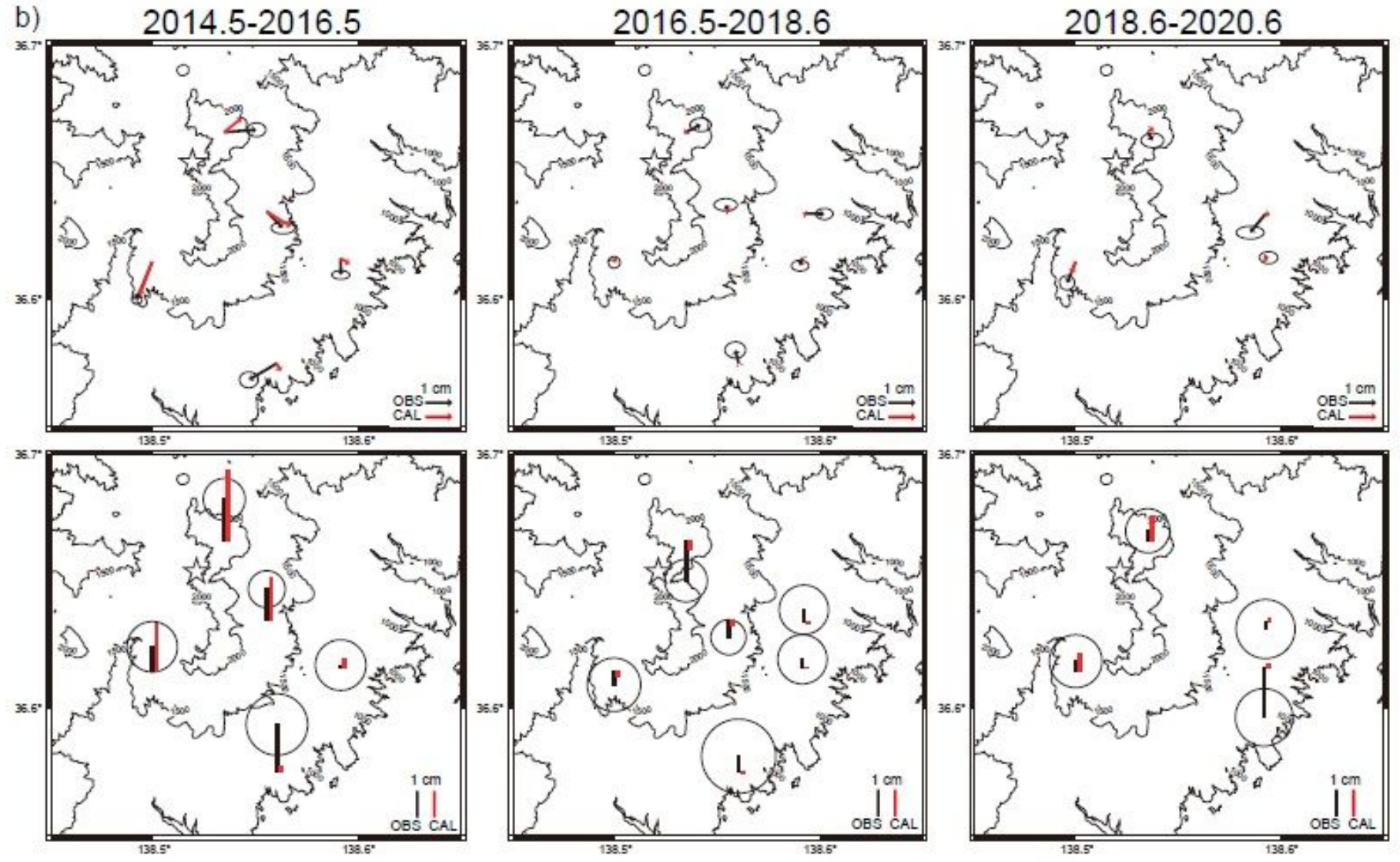

Figure 4

Location of source, and observed and calculated displacements at sites around Kusatsu-Shirane volcano. Location of estimated source and observed and calculated displacements at sites around KusatsuShirane volcano. (a): Location of source. (b): Observed and calculated displacements. Top three panels show horizontal displacements for three periods (2014.5-2016.5, 2016.5-2018.6, 2018.6-2020.6) and 
bottom three panels show those of vertical displacements. Error ellipsoids reflect 1 sigma observation errors.

a)

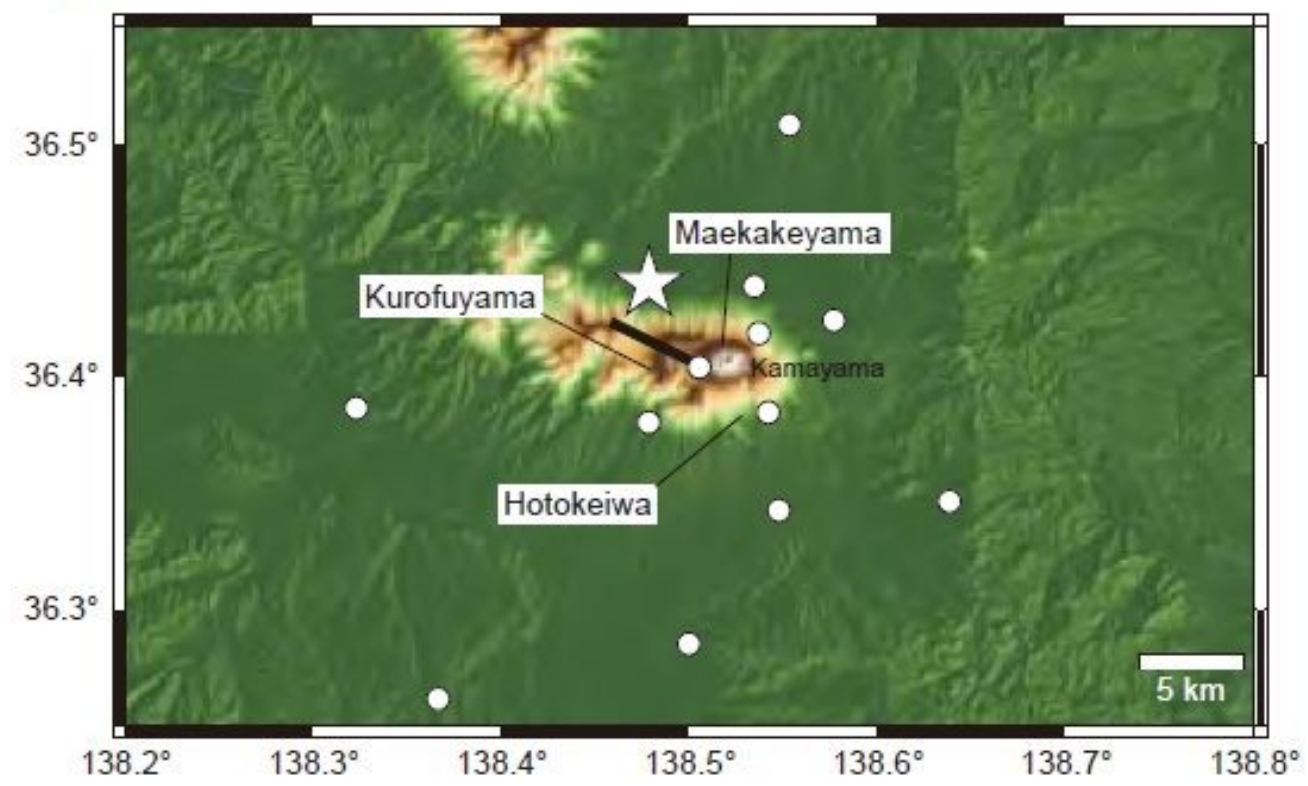

b) $\quad 2014.5-2016.5$

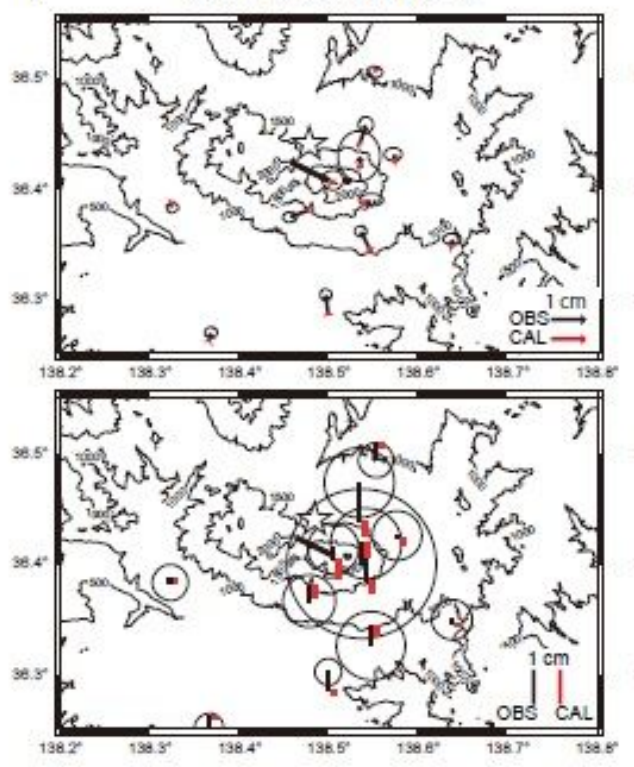

2016.5-2018.6

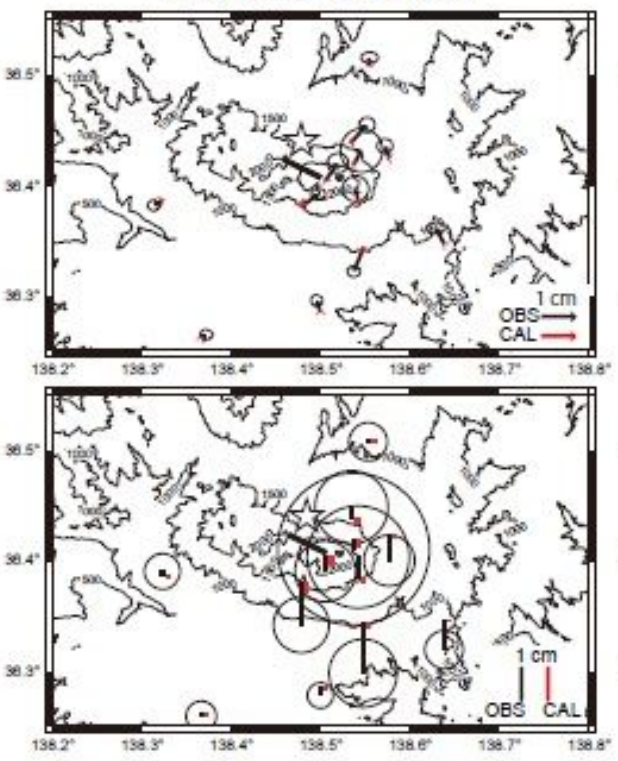

2018.6-2020.6

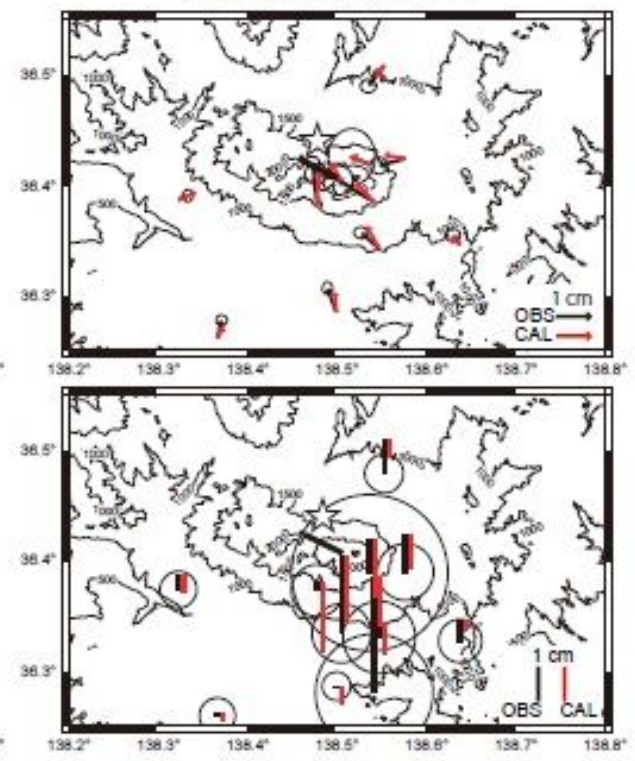

\section{Figure 5}

Location of sources, and observed and calculated displacements at sites around Asama volcano.

Location of sources, and observed and calculated displacements at sites around Asama volcano. (a): Location of the sources. (b): Observed and calculated displacements. Legends are the same as for Figure 4. 

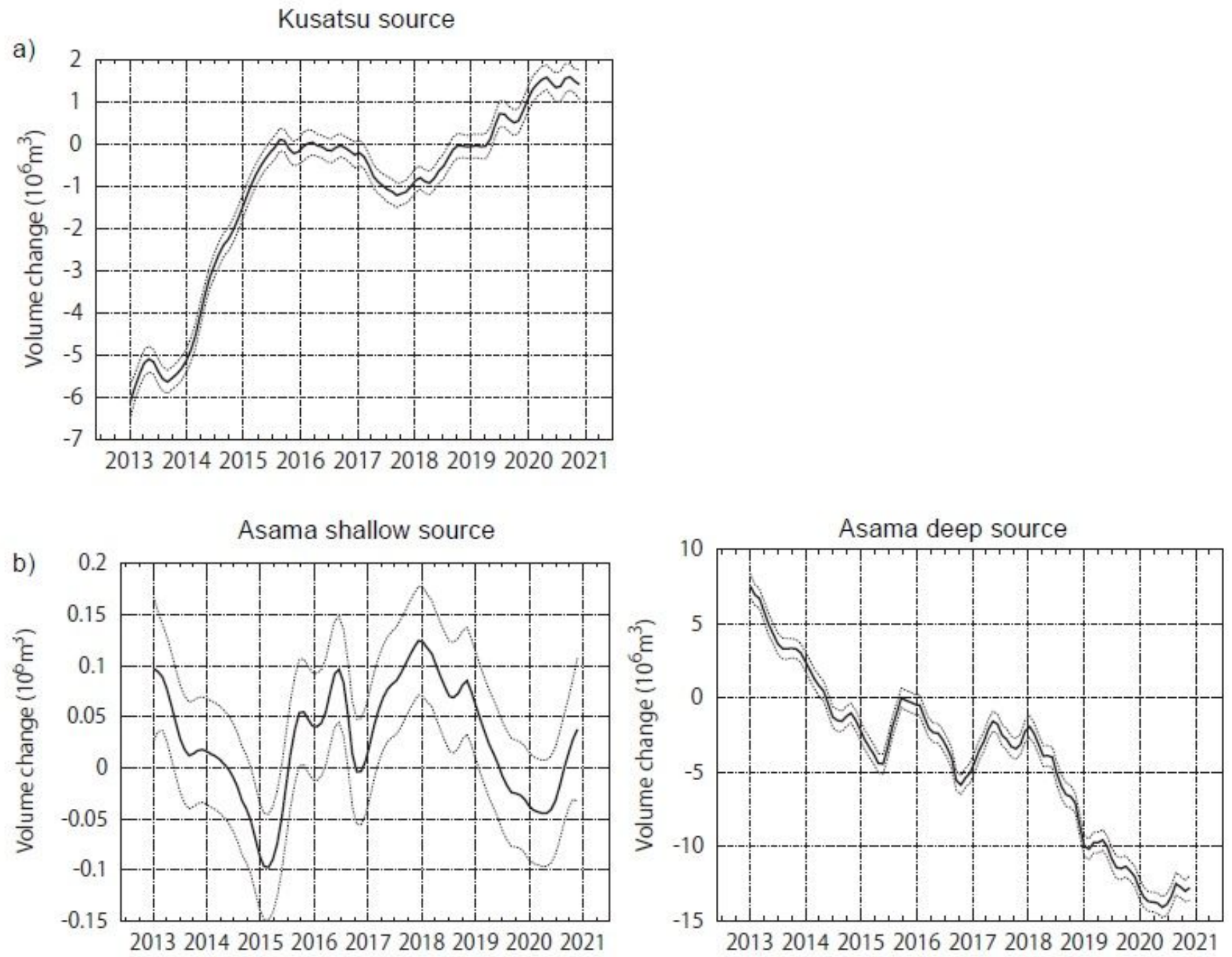

Figure 6

Estimated volume changes for sources at Kusatsu-Shirane and Asama volcanoes. Estimated volume changes for sources at Kusatsu-Shirane and Asama volcanoes. a) Volume changes of Kusatsu-Shirane source. b) Volume changes of Asama sources. Left and right panels show those of shallow and deep sources, respectively. Dashed lines represent 1 sigma credible intervals. 
a)

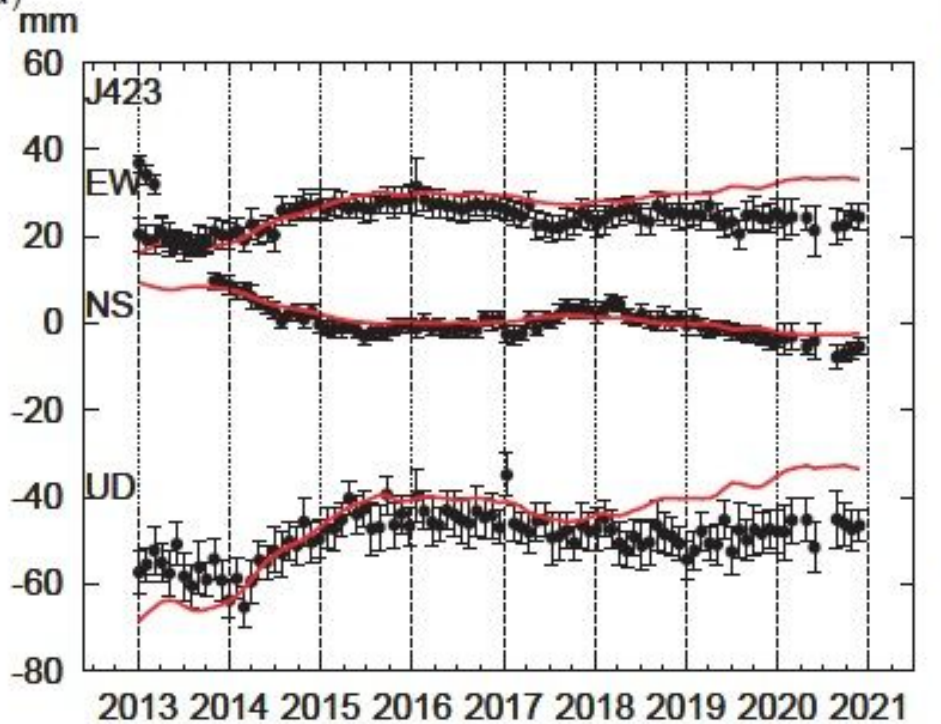

b)

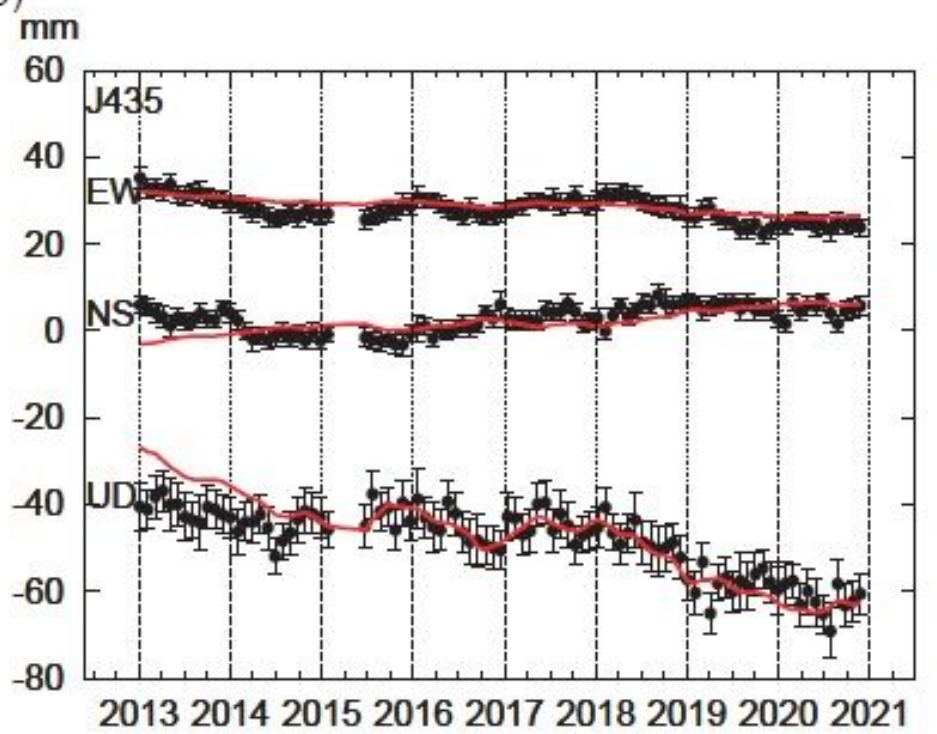

$\mathrm{mm}$

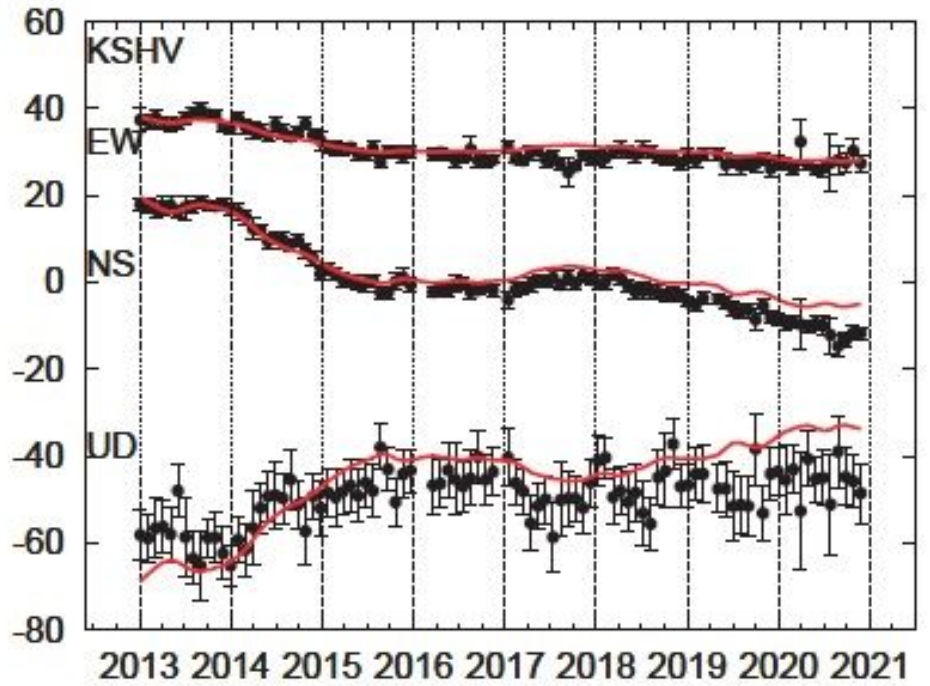

$\mathrm{mm}$

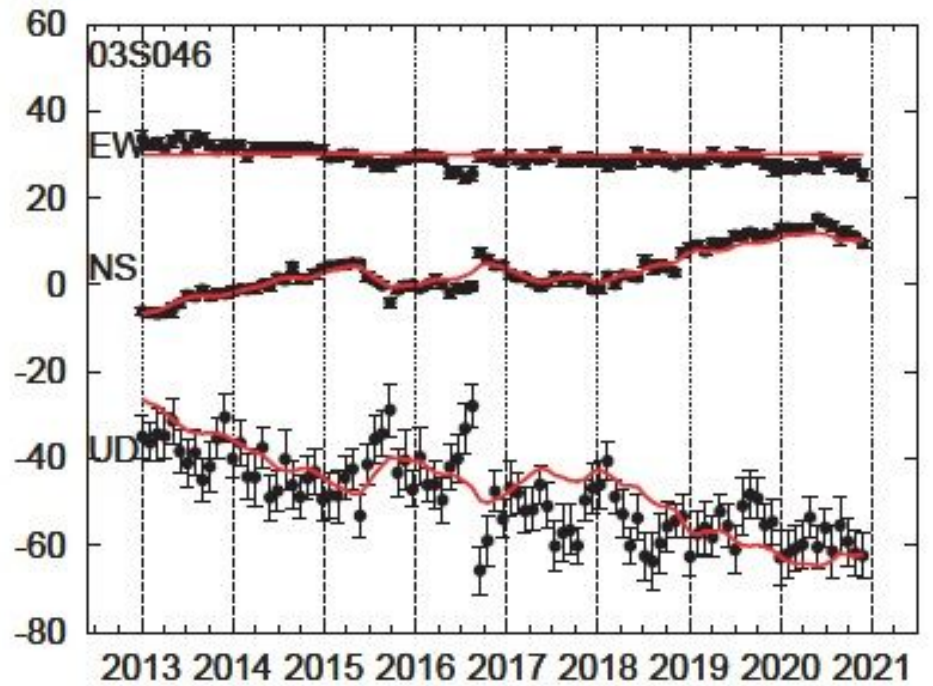

\section{Figure 7}

Observed and calculated GNSS coordinate time series after linear inversion at selected sites. Observed and calculated GNSS coordinate time series after linear inversion at selected sites. a) Selected GNSS coordinate time series for sites around Kusatsu-Shirane volcano, b) Those for sites around Asama volcano. Error bars represent 1 sigma observation errors. Complete GNSS coordinate time series are given in Figures S2(a) and S2(b).

\section{Supplementary Files}

This is a list of supplementary files associated with this preprint. Click to download.

- SupplementaryMaterial.pdf 